\title{
Modelling and Analysis of Grid Integrated TSCAOI Generators for Renewable Distributed Generation Systems
}

\author{
Zhijia Wang and Udaya Kumara Madawala
}

\begin{abstract}
Behaviour of 3-phase cage induction machines, operated in two series-connected and one isolated (TSCAOI) phase winding configuration at variable speeds to generate singlephase electricity, has been investigated in detail for standalone applications. However, integration of TSCAOI configured 3-phase cage induction machines into single-phase distributed power systems is yet to be investigated. This paper therefore presents a model to investigate the behaviour of grid-connected TSCAOI generator systems and proposes a control strategy to regulate the amount of electricity generation at unity power factor under different operating conditions. Additionally, for further simplifying the overall system, a slip estimation method is proposed to enable the speed-sensorless operation of the generator. In order to validate the system feasibility, a prototype grid-connected TSCAOI generator is to be regulated, with balanced operation, to generate electricity to the grid at unity power factor. Good agreement between theoretical and experimental results under various operating conditions indicates that the generator can be successfully regulated by the proposed control scheme and are expected to be suitable for applications, such as small-scale wind and micro-hydro distributed generation systems.
\end{abstract}

Index Terms-Grid-connected mode, renewable energy conversion, small-scale induction generator.

\section{INTRODUCTION}

S USTAINABLE development is a major challenge at present. Every new unit of economic growth is still attained at the expense of depletion of the natural energy resources and degradation of the environment. One of the major reasons for this is the world's heavy reliance on fossil fuels. Fossil fuels are non-renewable energy sources, meaning that there is a finite amount of fossil fuels available and they do not naturally replenish fast enough. In addition, fossil fuels need to be burned to release the stored energy. However, the burning of fossil fuels also releases harmful particles and greenhouse gases into the atmosphere, resulting in adverse environmental effects. At present, for instance, around $91 \%$ of the world population live amid unsafe outdoor air pollution, which causes more than 4 million deaths each year [1]. Around $90 \%$ of the global

Manuscript received December 27, 2019; revised June 1, 2020; accepted July 7, 2020. Date of publication December 30, 2020; date of current version December 17, 2020.

Both authors are with Department of Electrical and Computer Engineering, the University of Auckland, 1142 Auckland, New Zealand (e-mail: zwan169@, aucklanduni.ac.nz; u.madawala@auckland.ac.nz).

Digital Object Identifier 10.24295/CPSSTPEA.2020.00031 greenhouse gases emissions are sourced from the burning of fossil fuels [2].

In order to reduce the reliance on fossil fuels, it has become a consensus among countries of the world to focus more on renewable energy. Unlike non-renewable energy, renewable energy comes from sources that are naturally replenished in a relatively short timeframe. Sources of renewable energy mainly include wind, hydro, solar, geothermal and biomass. Another important advantage is that renewable energy is a clean source of energy. Wind, hydroelectric and solar systems generate electricity without air pollution and greenhouse emissions. Geothermal and biomass systems emit some greenhouse gases, however the emissions are much lower than those of burning fossil fuels.

Unlike the fossil fuels, which heavily relies on the transport lines, renewable energy sources are broadly available and distributed. Distributed generation therefore becomes a promising paradigm for the renewable energy systems. Due to the distributed nature of renewable energy sources, these distributed generation systems are usually small-scale in terms of power rating, thus may not be as efficient as large scale centralised generation systems. However, this disadvantage is offset by the cost reduction of the transmission and distribution grid.

In recent years, renewable distributed generation using small scale generating units of power rating less than $200 \mathrm{~kW}$ has drawn particular attentions [3], [4]. Because, on one hand, this small scale renewable distributed generating system is quite suitable to provide electricity for homes, businesses and farms in remote areas. On the other hand, the global trend of energy deregulation encourages the development of such systems. More importantly, at present, about 1 billion people still lack access to electricity, and the vast majority of them are living in the rural areas of Africa and Asia-Pacific [5]. The small scale renewable distributed generation system has great potential to help provide basic electricity service to those people who are living without electricity.

The majority of small scale renewable generation systems use electric generators to convert kinetic energy into electrical energy, except the photovoltaic (PV) systems. Among these electric generators, squirrel cage induction generators (SCIGs) are the cheapest and most rugged, thus most widely used. In remote and rural areas, the population is sparsely distributed, and the most of electric loads are of single-phase nature. Therefore, single-phase SCIG is preferred over 3-phase SCIG to make the whole system simple and cost-effective. Using single-phase SCIGs means that for a given amount of capital investment, more areas can gain access to electricity. 


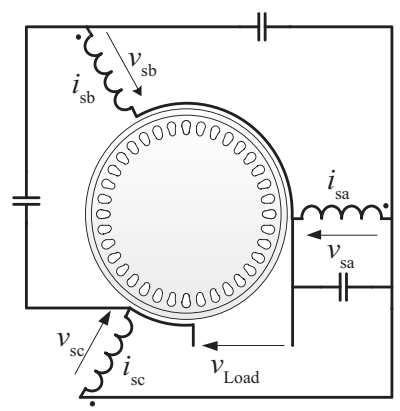

(a)

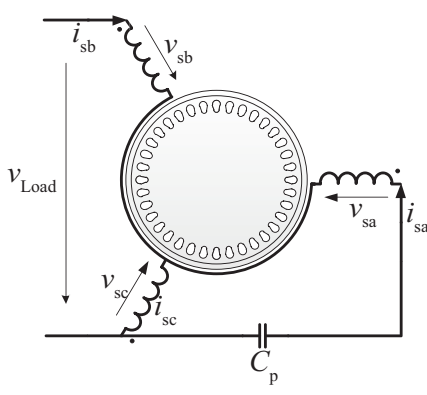

(b)

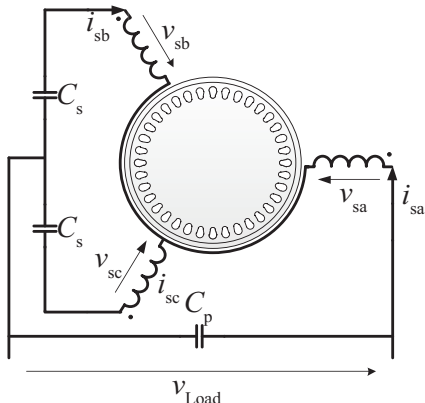

(c)

Fig. 1. 3-phase SCIG with single-phase output. (a) Smith connection. (b) Steinmetz connection. (c) Fukami connection.

Single-phase squirrel cage induction machines (SCIMs) can be used for single-phase electricity generation [3], [4], but use of conventional 3-phase SCIMs for single-phase electricity generation is more advantageous over single-phase machines, especially for machines with power ratings above $3 \mathrm{~kW}$ [5], [6]. This is because 3-phase SCIMs are widely available in the market, and more economical in terms of both size and cost than its single-phase counterparts. Therefore, use of 3-phase SCIMs for single-phase electricity generation has been of interest to both academia and industry and consequently been widely explored. However, when a 3-phase SCIM is operated as a single-phase generator, the 3-phase stator currents are generally unbalanced. Therefore, output power degradation is normally inevitable. Furthermore, the adverse effects such as mechanical vibration, poor efficiency, thermal overload and uncontrollable power factor are also concerned [7]. Hence, various phase balancing techniques have been proposed and investigated to mitigate these concerns. In general, all these techniques can be classified into two categories: namely based on passive circuit elements and power electronic converters.

In the method proposed by [6], a steady-state power system balancer was investigated to resolve the aforementioned unbalanced conditions. By using a capacitance and an inductance of identical reactance, the power system balancer is able to balance the stator currents. However, the series resonance between the capacitance and inductance caused severe over voltages when the specified operating point is changed. The 3-phase SCIM in Smith connection, shown in Fig. 1(a), was proposed in [7]. It removed the danger of the resonance effect using capacitors exclusively. Additionally, it was capable of balancing stator phase currents for medium and heavy loads [8]-[10].

The Steinmetz connection, shown in Fig. 1(b), is also widely used to balance 3-phase SCIGs operated in singlephase mode due to its simple configuration [11]-[13]. In contrast to the Smith connection, this method is applicable for 3-phase SCIMs with stator windings configured in both star and delta connections. With properly selected capacitance and operating speed, the perfect phase balance can be achieved through this connection. Another phase balancing scheme, proposed in [14], is illustrated in Fig. 1(c). It introduced series compensation capacitors to improve the regulation of output voltage. However, with this technique, it is more difficult to balance phase currents and the machine utilization is poor [15], [16]. Current injection method [17] and SCIGs with $\mathrm{C}-2 \mathrm{C}$ connection [18] have also been investigated as phase balancing techniques. Although all these passive circuit elements based techniques are able to balance the machine at a specific operating speed and load, the regulation of both power and voltage with balanced operating conditions is very difficult to achieve under dynamic load and variable speed conditions. Additionally, these techniques have some inherent drawbacks such as self-excitation failure [19], [20], sensitivity to operating parameters [21], [22] and poor voltage and frequency regulations [23], [24]. Nonetheless, many attempts have been made to overcome these difficulties through various modifications to the existing techniques, including multi-mode operation for SCIGs with Smith connection [8], [25], SCIGs with different modified Steinmetz connections [26], [27] and Fukami configuration with damping resistance [16]. However, these modifications caused increased complexity and cost with limited improvement in performance.

With both the advances and reduction in cost in semiconductor devices, power electronic converters with active control started to emerge as an alternative approach to improve dynamic response as well as voltage and frequency regulation capability of the 3-phase SCIM based single-phase electricity generation systems. Methods in [28]-[30] employed two fullbridge converters in back-to-back configuration, as shown in Fig. 2(a), to improve the performance of the generator. However, the use of two full capacity converters with a bulky filter considerably increases the cost and size as well as the complexity of the system. As illustrated in Fig. 2(b), singlephase electricity could also be generated using a 3-phase SCIM with a combination of 3-phase converters and dump load [31], [32], but at the expense of significant power losses in the dump load and large output voltage drop under heavy load conditions. In [33], [34], an electronic load controller (ELC), as depicted in Fig. 2(c), was proposed to assist 3-phase SCIM in delta connection for standalone single-phase power generation, and subsequently extended for star connected 3-phase SCIMs with Fukami configuration [35]. Although this scheme provides a relatively low-cost and simple solution for 3-phase 


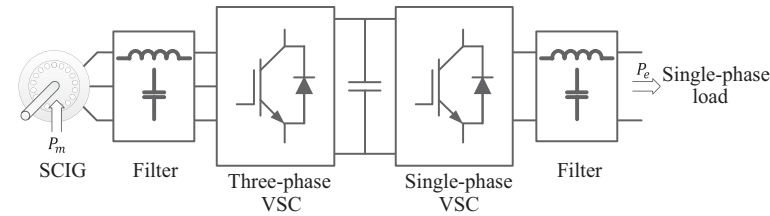

(a)

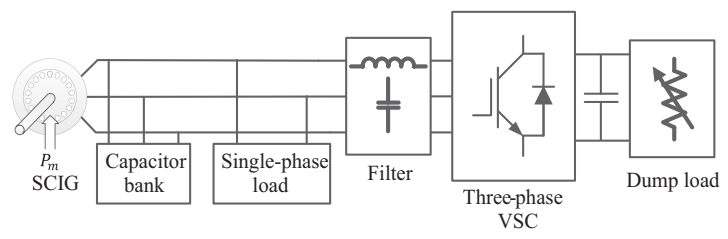

(b)

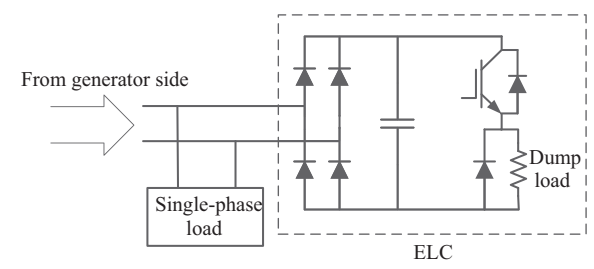

(c)

Fig. 2. Plots for: (a) The back-to-back configuration for 3-phase SCIGs feeding single-phase load. (b) The voltage source converter (VSI) and dump load based configuration. (c) The structure of electronic load controller (ELC).

SCIM based single-phase power generation system, it is only applicable under constant input power conditions and suffers from low-efficiency and high harmonic distortion at output.

The techniques, which are based on passive circuit elements, have the advantages of low cost, low maintenance and simple configuration. However, these techniques share two common weaknesses. One is the poor output voltage and frequency regulation and the other is the limited operating range. Conversely, the techniques, which are based on power converters, have better voltage and frequency regulation capabilities and wider operating range but at the expense of higher cost and complicated configurations.

As an alternative, a new winding configuration, that uses one of the stator phases of a 3-phase SCIM as the excitation winding and the remaining two phases connected in series as the power winding, has been proposed [36]-[40]. This decoupled winding configuration is named as two-series connected and one isolated (TSCAOI) and shown in Fig. 3 . In contrast to other power converter based techniques, the TSCAOI configured generator also combines the cost advantage of the passive circuit element based techniques, by only using a bi-directional single-phase converter. In addition, it enables direct single-phase electricity generation without using a power conversion stage, thus also having the advantage of low harmonic distortion.

The single-phase electricity is generated through the power winding directly. Variable reactive power required by the TSCAOI configured generator is provided through the excitation winding by a small scale bi-directional converter. The bi-directional converter is connected with an energy-

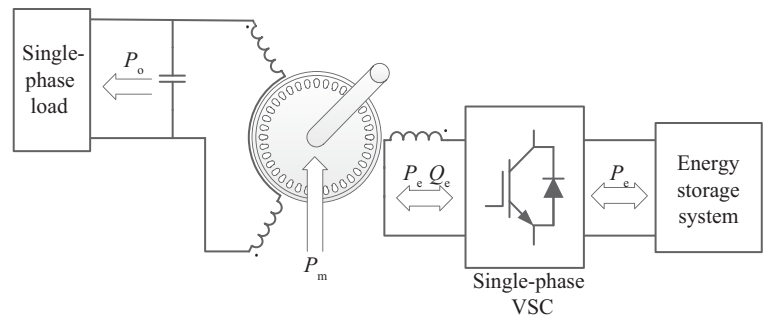

Fig. 3. The TSCAOI configuration for 3-phase SCIMs feeding single-phase load.

storage-system (ESS). In practice, a PV panel can be integrated into the ESS, enabling hybrid renewable energy generation (HREG) which can significantly improve the system reliability and energy utilization.

Behaviour of 3-phase cage induction machines, operated in the TSCAOI winding configuration at variable speeds to generate single-phase electricity, has been investigated in detail for standalone renewable power generation systems [36]-[40]. However, integration of TSCAOI configured 3-phase cage induction machines into single-phase distributed power system is yet to be investigated. This paper therefore first investigates the behaviour of the grid-connected TSCAOI generator, and proposes a control scheme for integrating the TSCAOI configured generators into the single-phase distributed power system.

Firstly, a steady-state model is presented to investigate the behaviour of the grid-connected TSCAOI generator. Secondly, the operating criterion is formulated for the grid-connected TSCAOI generators, considering the following three aspects, namely the grid-side power factor, the torque fluctuation and the operating voltages and currents of the machines. From the investigation of the proposed model, it is found that there exists mutual coupling among these three aspects of the proposed criterion. Moreover, the coupling makes it very difficult to operate the generator to fulfil the proposed criterion at variable speeds, using real-time computed excitation winding voltage. In order to overcome this issue, this paper therefore proposes a look-up table (LUT) method, using pre-computed optimum excitation voltage at different operating speeds. Thirdly, to further simplify the overall system, a slip estimation method is proposed to enable speed-sensorless control of the generator. Finally, the validity of the proposed generator concept is verified through simulations, implementing the proposed model in MATLAB/Simulink and experimental evidence of a prototype generator in this paper. Good agreement between simulated and experimental results under various operating conditions indicates that the generator can be successfully grid integrated by the proposed control scheme and is suitable for applications, such as small-scale wind and micro-hydro distributed generation systems.

\section{Mathematical Model}

As derived in [38], the dynamic behaviour of the TSCAOI configured SCIM can be described by the following equations in the stationary $\alpha \beta$ frame, with the $\alpha$-axis of the frame being aligned with the magnetic axis of the one isolated (OI) winding: 


$$
\begin{gathered}
{\left[\begin{array}{c}
v_{\mathrm{se}} \\
v_{\mathrm{so}}^{\prime} \\
0 \\
0
\end{array}\right]=\left[\begin{array}{cc}
R_{\mathrm{s}}+\left(L_{\mathrm{ls}}+L_{\mathrm{m}}\right) p & 0 \\
0 & \frac{2}{3} R_{\mathrm{s}}+\left(\frac{2}{3} L_{\mathrm{ls}}+L_{\mathrm{m}}\right) p \\
L_{\mathrm{m}} p & \omega_{\mathrm{r}} L_{\mathrm{m}} \\
-\omega_{\mathrm{r}} L_{\mathrm{m}} & L_{\mathrm{m}} p \\
L_{\mathrm{m}} p & 0 \\
0 & L_{\mathrm{m}} p \\
\frac{2}{3} R_{\mathrm{r}}+\left(\frac{2}{3} L_{\mathrm{lr}}+L_{\mathrm{m}}\right) p & \omega_{\mathrm{r}}\left(\frac{2}{3} L_{\mathrm{lr}}+L_{\mathrm{m}}\right) \\
-\omega_{\mathrm{r}}\left(\frac{2}{3} L_{\mathrm{lr}}+L_{\mathrm{m}}\right) & \frac{2}{3} R_{\mathrm{r}}+\left(\frac{2}{3} L_{\mathrm{lr}}+L_{\mathrm{m}}\right) p
\end{array}\right]\left[\begin{array}{c}
i_{\mathrm{se}} \\
i_{\mathrm{so}}^{\prime} \\
i_{\mathrm{r} \alpha} \\
i_{\mathrm{r} \beta}^{\prime}
\end{array}\right]} \\
T_{\mathrm{e}}=\frac{P}{2} L_{\mathrm{m}}\left(i_{\mathrm{so}}^{\prime} i_{\mathrm{r} \alpha}^{\prime}-i_{\mathrm{se}} i_{\mathrm{r} \beta}^{\prime}\right) \\
T_{\mathrm{e}}-T_{\mathrm{ex}}=\frac{2 J}{P} \frac{\mathrm{d} \omega_{\mathrm{r}}}{\mathrm{d} t}
\end{gathered}
$$

In (1), variables $v_{\mathrm{so}}^{\prime}$ and $i_{\mathrm{so}}^{\prime}$ are the referred voltage and current of the power winding, and $v_{\mathrm{se}}$ and $i_{\mathrm{se}}$ are the variables of the excitation winding. Variables $i_{\mathrm{r} \alpha}^{\prime}$ and $i_{\mathrm{r} \beta}^{\prime}$ represent the referred $\alpha$ and $\beta$ components of the rotor currents respectively. In addition, $p$ represents the differential operator $\mathrm{d} / \mathrm{d} t$, parameters $R_{\mathrm{s}}, L_{\mathrm{ls}}$, $L_{\mathrm{m}}, R_{\mathrm{r}}$ and $L_{\mathrm{lr}}$ represent the stator resistance, the stator leakage inductance, the magnetizing inductance, the rotor resistance and the rotor leakage inductance of the 3-phase SCIM, respectively, and $\omega_{\mathrm{r}}$ is the electrical angular frequency of the rotor in rad/s. The electromagnetic torque applied on the rotor shaft is given in (2), where $P$ is the number of poles. The motion of the machine is described in (3) subsequently, where $J$ is the rotor inertia in $\mathrm{kg} \cdot \mathrm{m}^{2}, T_{\mathrm{e}}$ is the electromagnetic torque, in $N_{\mathrm{m}}$ and $T_{\mathrm{ex}}$ is the external torque, applied on the rotor shaft, in $N_{\mathrm{m}}$.

The steady-state voltage equations of the gird-connected TSCAOI configured generator can be readily obtained via replacing the differential operator $p$ by $j \omega_{\text {grid }}$, where $\omega_{\text {grid }}$ is the grid angular frequency, and consequently expressed using phasor variables as:

$$
\begin{gathered}
{\left[\begin{array}{c}
\widetilde{V}_{\mathrm{se}} \\
\widetilde{V}_{\mathrm{so}}^{\prime} \\
0 \\
0
\end{array}\right]=\left[\begin{array}{cc}
R_{\mathrm{s}}+j \omega_{\text {grid }}\left(L_{\mathrm{ls}}+L_{\mathrm{m}}\right) & 0 \\
0 & \frac{2}{3} R_{\mathrm{s}}+j \omega_{\text {grid }}\left(\frac{2}{3} L_{\mathrm{ls}}+L_{\mathrm{m}}\right) \\
j \omega_{\text {grid }} L_{\mathrm{m}} & \omega_{\mathrm{r}} L_{\mathrm{m}} \\
-\omega_{\mathrm{r}} L_{\mathrm{m}} & j \omega_{\mathrm{grid}} L_{\mathrm{m}} \\
j \omega_{\text {grid }} L_{\mathrm{m}} & 0 \\
0 & j \omega_{\text {grid }} L_{\mathrm{m}} \\
\frac{2}{3} R_{\mathrm{r}}+j \omega_{\text {grid }}\left(\frac{2}{3} L_{\mathrm{lr}}+L_{\mathrm{m}}\right) & \omega_{\mathrm{r}}\left(\frac{2}{3} L_{\mathrm{lr}}+L_{\mathrm{m}}\right) \\
-\omega_{\mathrm{r}}\left(\frac{2}{3} L_{\mathrm{lr}}+L_{\mathrm{m}}\right) & \frac{2}{3} R_{\mathrm{r}}+j \omega_{\text {grid }}\left(\frac{2}{3} L_{\mathrm{lr}}+L_{\mathrm{m}}\right)
\end{array}\right]\left[\begin{array}{c}
\tilde{I}_{\mathrm{se}} \\
\tilde{I}_{\mathrm{so}}^{\prime} \\
\tilde{I}_{\mathrm{rr}}^{\prime} \\
\tilde{I}_{\mathrm{r}}^{\prime}
\end{array}\right]}
\end{gathered}
$$

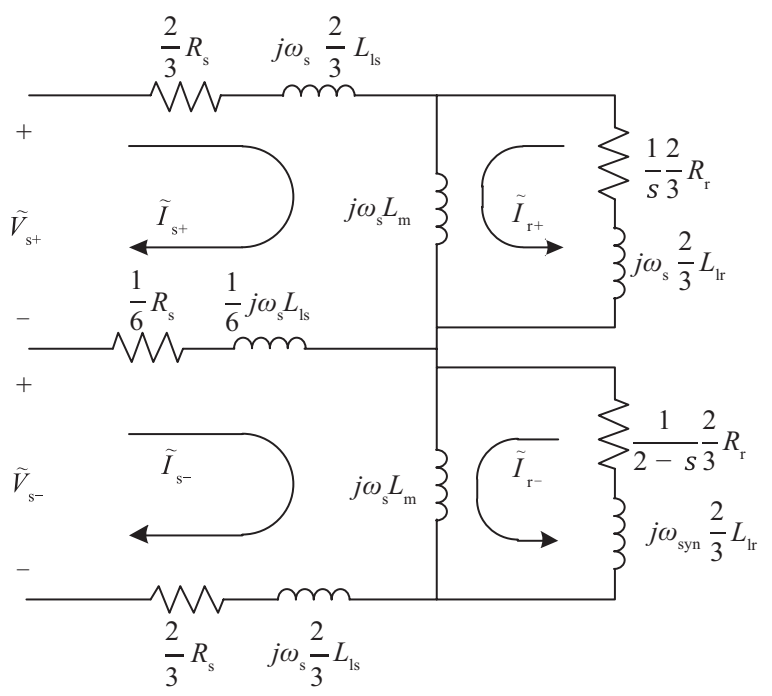

Fig. 4. The steady-state equivalent circuit of the grid-connected TSCAOI configured 3-phase SCIG.

The method of symmetrical components is employed to develop the generalized steady-state equivalent circuit model that will be used to investigate the behaviour and performance of this grid-connected generator. By appropriately selecting the transformation matrix $[S]$ as:

$$
[S]=\left[\begin{array}{cc}
j & -j \\
1 & 1
\end{array}\right]
$$

The steady-state voltage equations in terms of the symmetrical components can be obtained as:

$$
\begin{gathered}
{\left[\begin{array}{l}
\widetilde{V}_{\mathrm{s}+} \\
\widetilde{V}_{\mathrm{s}-} \\
0 \\
0
\end{array}\right]=\left[\begin{array}{cc}
\frac{5}{6} R_{\mathrm{s}}+\frac{5}{6} j \omega_{\text {grid }} L_{\mathrm{ls}}+j \omega_{\text {grid }} L_{\mathrm{m}} & -\frac{1}{6} R_{\mathrm{s}}-\frac{1}{6} j \omega_{\text {grid }} L_{\mathrm{ls}} \\
-\frac{1}{6} R_{\mathrm{s}}-\frac{1}{6} j \omega_{\text {grid }} L_{\mathrm{ls}} & \frac{5}{6} R_{\mathrm{s}}+\frac{5}{6} j \omega_{\text {grid }} L_{\mathrm{ls}}+j \omega_{\text {grid }} L_{\mathrm{m}} \\
j \omega_{\text {grid }} L_{\mathrm{m}} & 0 \\
0 & j \omega_{\text {grid }} L_{\mathrm{m}} \\
j \omega_{\text {grid }} L_{\mathrm{m}} & 0 \\
0 & j \omega_{\text {grid }} L_{\mathrm{m}} \\
\frac{1}{s} \frac{2}{3} R_{\mathrm{r}}+j \omega_{\text {grid }}\left(\frac{2}{3} L_{\mathrm{lr}}+L_{\mathrm{m}}\right) & 0 \\
0 & \frac{1}{2-s} \frac{2}{3} R_{\mathrm{r}}+j \omega_{\text {grid }}\left(\frac{2}{3} L_{\mathrm{lr}}+L_{\mathrm{m}}\right)
\end{array}\right]}
\end{gathered}
$$

where $s$ is the slip. The positive sequence and negative sequence symmetrical components are denoted by subscripts $s^{+}$and $s^{-}$, respectively.

The above equations can be represented by the steady-state equivalent circuit shown in Fig. 4.

For clarity, let

$$
Z_{1}=\frac{5}{6} R_{\mathrm{s}}+\frac{5}{6} j \omega_{\mathrm{s}} L_{\mathrm{ls}}+\frac{j \omega_{\mathrm{s}} L_{\mathrm{m}}\left(\frac{1}{s} \frac{2}{3} R_{\mathrm{r}}+j \omega_{\mathrm{s}} \frac{2}{3} L_{\mathrm{lr}}\right)}{\frac{1}{s} \frac{2}{3} R_{\mathrm{r}}+j \omega_{\mathrm{s}}\left(L_{\mathrm{m}}+\frac{2}{3} L_{\mathrm{lr}}\right)}
$$




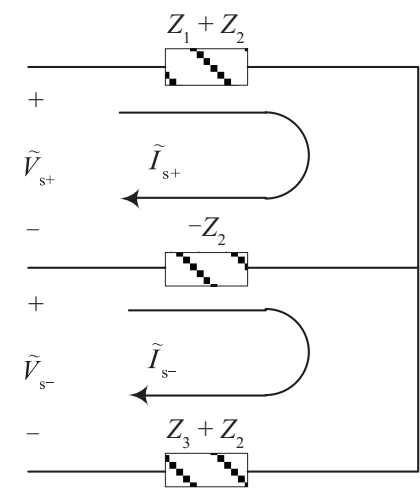

Fig. 5. Simplified steady-state equivalent circuit.

$$
\begin{gathered}
Z_{2}=-\frac{1}{6} R_{\mathrm{s}}-\frac{1}{6} j \omega_{\mathrm{s}} L_{\mathrm{ls}} \\
Z_{3}=\frac{5}{6} R_{\mathrm{s}}+\frac{5}{6} j \omega_{\mathrm{s}} L_{\mathrm{ls}}+\frac{j \omega_{\mathrm{s}} L_{\mathrm{m}}\left(\frac{1}{2-s} \frac{2}{3} R_{\mathrm{r}}+j \omega_{\mathrm{s}} \frac{2}{3} L_{\mathrm{lr}}\right)}{\frac{1}{2-s} \frac{2}{3} R_{\mathrm{r}}+j \omega_{\mathrm{s}}\left(L_{\mathrm{m}}+\frac{2}{3} L_{\mathrm{lr}}\right)}
\end{gathered}
$$

With the impedances defined above, the steady-state equivalent circuit model shown in Fig. 4 can be accordingly simplified to the model shown in Fig. 5.

The symmetrical components of the stator voltages can therefore be expressed in terms of the stator currents symmetrical components with newly defined impedances as:

$$
\begin{aligned}
& \tilde{V}_{\mathrm{s}+}=Z_{1} \tilde{I}_{\mathrm{s}+}+Z_{2} \tilde{I}_{\mathrm{s}-} \\
& \tilde{V}_{\mathrm{s}-}=Z_{2} \tilde{I}_{\mathrm{s}+}+Z_{3} \tilde{I}_{\mathrm{s}-}
\end{aligned}
$$

The symmetrical components of the stator currents can be accordingly obtained by solving (10) and (11) simultaneously as:

$$
\begin{aligned}
& \tilde{I}_{\mathrm{s}+}=\left(Z_{3} \tilde{V}_{\mathrm{s}+}-Z_{2} \tilde{V}_{\mathrm{s}-}\right) / Z_{\mathrm{m}} \\
& \tilde{I}_{\mathrm{s}-}=\left(Z_{1} \tilde{V}_{\mathrm{s}-}-Z_{2} \tilde{V}_{\mathrm{s}+}\right) / Z_{\mathrm{m}}
\end{aligned}
$$

where $Z_{\mathrm{m}}=Z_{1} Z_{3}-\left(Z_{2}\right)^{2}$.

Based on the inverse of the transformation matrix given in (5), the symmetrical components of stator voltages can be written as

$$
\begin{gathered}
\widetilde{V}_{\mathrm{s}+}=-\frac{j}{2} \widetilde{V}_{\mathrm{se}}+\frac{1}{2} \widetilde{V}_{\mathrm{so}}^{\prime} \\
\widetilde{V}_{\mathrm{s}-}=\frac{j}{2} \widetilde{V}_{\mathrm{se}}+\frac{1}{2} \widetilde{V}_{\mathrm{so}}^{\prime}
\end{gathered}
$$

For simplicity, the referred power winding phasor voltage is fixed as reference to be $\tilde{V}_{\text {so }}^{\prime}=V_{\text {so }}^{\prime} \angle 0^{\circ}=V_{\text {so }}^{\prime}$, where $V_{\text {so }}^{\prime}$ is the referred grid voltage amplitude; the excitation winding phasor voltage is represented in terms of its real and imaginary components as $\tilde{V}_{\text {se }}=V_{\text {seR }}+j V_{\text {sel}}$, where $V_{\text {seR }}$ and $j V_{\text {sel }}$ denote the real part and the imaginary part of the excitation winding phasor voltage, respectively.

Accordingly, the phasors of the stator voltage symmetrical components, given in (14) and (15), can be further expressed, in terms of its real and imaginary components, as:

$$
\begin{aligned}
& \widetilde{V}_{\mathrm{s}+}=\frac{1}{2}\left(V_{\mathrm{sel}}+V_{\mathrm{so}}^{\prime}\right)-\frac{j}{2} V_{\mathrm{seR}} \\
& \widetilde{V}_{\mathrm{s}-}=\frac{1}{2}\left(V_{\mathrm{so}}^{\prime}-V_{\mathrm{sel}}\right)+\frac{j}{2} V_{\mathrm{seR}}
\end{aligned}
$$

Substituting (16) and (17) into (12) and (13), the phasors of the stator current symmetrical components can be further given as:

$$
\begin{aligned}
\tilde{I}_{\mathrm{s}+}= & \frac{1}{2} \frac{Z_{3}}{Z_{\mathrm{m}}}\left(V_{\mathrm{sel}}+V_{\mathrm{so}}^{\prime}-j V_{\mathrm{seR}}\right) \\
& -\frac{1}{2} \frac{Z_{2}}{Z_{\mathrm{m}}}\left(V_{\mathrm{so}}^{\prime}-V_{\mathrm{sel}}+j V_{\mathrm{seR}}\right) \\
\tilde{I}_{\mathrm{s}-}= & \frac{1}{2} \frac{Z_{1}}{Z_{\mathrm{m}}}\left(V_{\mathrm{so}}^{\prime}-V_{\mathrm{sel}}+j V_{\mathrm{seR}}\right) \\
& -\frac{1}{2} \frac{Z_{2}}{Z_{\mathrm{m}}}\left(V_{\mathrm{sel}}+V_{\mathrm{so}}^{\prime}-j V_{\mathrm{seR}}\right)
\end{aligned}
$$

Based on the transformation matrix [S], defined in (5), the current flowing through the power winding can be obtained as follows:

$$
\begin{aligned}
\tilde{I}_{\mathrm{so}}^{\prime}=\tilde{I}_{\mathrm{s}+}+\tilde{I}_{\mathrm{s}-}= & \frac{1}{2} \frac{Z_{3}}{Z_{\mathrm{m}}}\left(V_{\mathrm{sel}}+V_{\mathrm{so}}^{\prime}-j V_{\mathrm{seR}}\right) \\
& +\frac{1}{2} \frac{Z_{1}}{Z_{\mathrm{m}}}\left(V_{\mathrm{so}}^{\prime}-V_{\mathrm{sel}}+j V_{\mathrm{seR}}\right)-\frac{Z_{2}}{Z_{\mathrm{m}}} V_{\mathrm{so}}^{\prime}
\end{aligned}
$$

In practice, a parallel compensation capacitor $C_{\text {comp }}$ is employed to compensate the reactive power requirement of the generator, therefore the actual grid current can be represented as:

$$
\tilde{I}_{\mathrm{g}}=\operatorname{abs}\left(\tilde{I}_{\mathrm{g}}\right) e^{j \theta_{\text {grid }}}=\frac{\tilde{I}_{\mathrm{so}}^{\prime}}{\sqrt{3}}+j \omega_{\mathrm{s}} C_{\mathrm{comp}} \tilde{V}_{\mathrm{so}}
$$

Where $\operatorname{abs}\left(\tilde{I}_{\mathrm{g}}\right)$ represents the absolute value of the grid current phasor and $\theta_{\text {grid }}$ is the grid current phasor angle.

The gird voltage phasor, being the same as the power winding voltage phasor, is fixed as reference. Therefore, the power factor (PF) at the grid side can be obtained by calculating the cosine of the grid current phasor angle as:

$$
P F=\cos \left(\theta_{\text {grid }}\right)
$$

Likewise, this asymmetrical winding arrangement will also cause the unbalanced operation of the generator, leading to torque fluctuation. As described previously, the difficulties in the manipulation of the fluctuating torque, make voltage unbalance factor (VUF) and current unbalance factor (CUF) widely adopted to approximate the level of torque fluctuation.

According to (16) and (17), the VUF, which is defined as the ratio of modulus of the negative-sequence to the positive- 
sequence components of the stator voltages, can be obtained as:

$$
V U F=\left|\frac{\widetilde{V}_{\mathrm{s}-}}{\widetilde{V}_{\mathrm{s}+}}\right|=\left|\frac{\left(V_{\mathrm{sel}}+V_{\mathrm{so}}^{\prime}\right)-j V_{\mathrm{seR}}}{\left(V_{\mathrm{so}}^{\prime}-V_{\mathrm{sel}}\right)+j V_{\mathrm{seR}}}\right|
$$

Similarly, according to (18) and (19), the CUF, which is defined as the ratio of modulus of the negative-sequence to the positive-sequence components of the stator currents, can be obtained as:

$C U F=\left|\frac{\tilde{I}_{\mathrm{s}-}}{\tilde{I}_{\mathrm{st}}}\right|=\left|\frac{Z_{3}\left(V_{\mathrm{sel}}+V_{\mathrm{so}}^{\prime}-j V_{\mathrm{seR}}\right)-Z_{2}\left(V_{\mathrm{so}}^{\prime}-V_{\mathrm{sel}}+j V_{\mathrm{seR}}\right)}{Z_{1}\left(V_{\mathrm{so}}^{\prime}-V_{\mathrm{sel}}+j V_{\mathrm{seR}}\right)-Z_{2}\left(V_{\mathrm{sel}}+V_{\mathrm{so}}^{\prime}-j V_{\mathrm{seR}}\right)}\right|$

It can be noted in (23) and (24) that the VUF is independent of the system parameters; conversely, the CUF is dependent on the system parameters.

The steady-state torque production of the generator, with a specific excitation voltage, can be obtained through simulation, implementing the proposed mathematical model in MATLAB/ Simulink. Then, the associated torque fluctuation amplitude can be readily calculated from the obtained torque production. By changing the real and imaginary part of the phasor of the excitation winding voltage respectively, the variations of the torque fluctuation amplitude with varying excitation voltages can be simulated.

A 3-kW, 4-pole 3-phase cage induction machine, with the parameters given in Appendix, was configured in the TSCAOI winding arrangement for the following simulations. Fig. 6 shows the simulated variations of the torque fluctuation amplitude with changing excitation voltages, when $s=-0.06$, $C_{\text {comp }}=20 \mu \mathrm{F}$ and the grid voltage is fixed at $230 \mathrm{~V} / 50 \mathrm{~Hz}$.

Where the $\tilde{V}_{\text {se_im }}$ and $\tilde{V}_{\text {se_e re }}$ are the imaginary and real part of the excitation winding phasor voltage respectively. As shown in Fig. 6, the torque fluctuation could be eliminated at a specific excitation voltage. In addition, it is noticeable that the larger the difference between the applied excitation voltage and this specific voltage, the larger the amplitude of the torque fluctuation will be.

The variations of VUF and CUF with changing excitation voltages can be obtained through simulation in the similar way, implementing (23) and (24) in MATLAB/Simulink respectively. The variations of VUF and CUF with changing excitation voltages are simulated, under the same operating conditions, and shown in Figs. 7 and 8, respectively. As evident, the CUF outperforms the VUF in approximating the level of torque fluctuations. Hence the CUF is selected to an indicator to represent the level of torque fluctuations approximately.

\section{Determination of the Excitation Winding Voltage}

In this section, the strategies for selecting the excitation

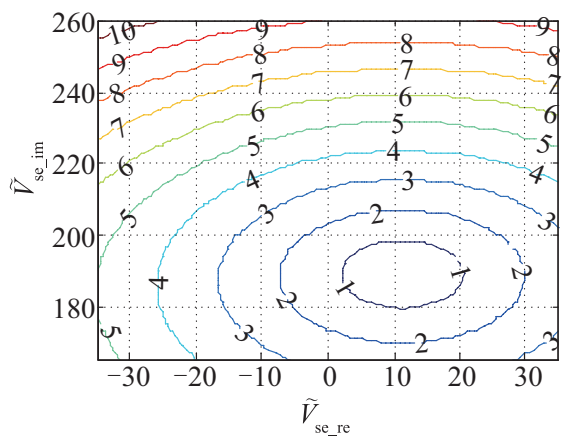

Fig. 6. Variations of the amplitude of the torque fluctuation with changing excitation voltages.

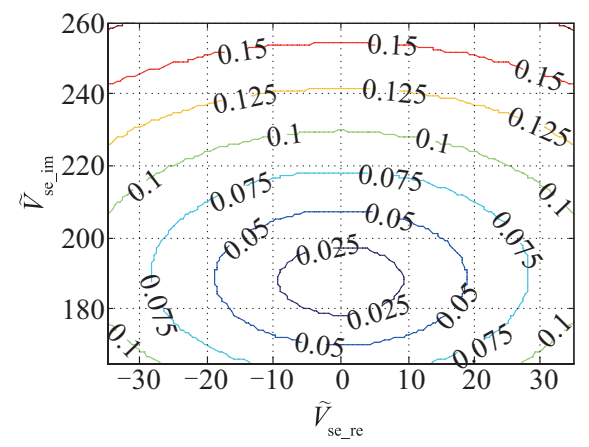

Fig. 7. Variations of VUF with changing excitation voltages.

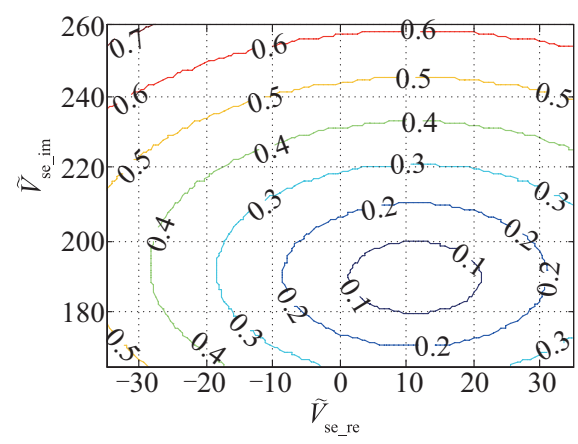

Fig. 8. Variations of CUF with changing excitation voltages.

winding voltage, which allows the generator to satisfy given criterion, is described. In order to demonstrate the viability of the proposed selection strategy, a 3-kW, 4-pole 3-phase cage induction machine, with the parameters given in Appendix, was configured in the TSCAOI winding arrangement, as a prototype generator, for the following numerical analysis.

The formulation of the operating criterion mainly considers three aspects, namely the grid-side power factor, the torque fluctuation and the maximum operating voltage and current.

Firstly, for the grid-side power factor, it is desirable to provide power to the single-phase grid at near-unity power factor in a majority of application scenarios. Secondly, for the torque fluctuation, in order to minimize the audible noise and mechanical vibrations caused by it, the amplitude of the torque fluctuation must be limited. Although, the torque fluctuation is difficult to be manipulated mathematically, it has been proven 
that the CUF can effectively approximate the level of the torque fluctuation in the last section. Hence, the CUF will replace the torque fluctuation to be limited. Finally, both the maximum operating voltage and current must be limited, considering the machine ratings, operating conditions and operating range.

The detailed operating criterion for this prototype generator is proposed according to the considerations above and listed as following:

- Generating active power to the single-phase grid at nearunity power factor (power factor $<-0.98$ ).

- Operating the generator with as small torque fluctuation as possible by maintaining the CUF under 0.05 .

- The operating phase currents and voltages are limited within $8.5 \mathrm{~A}$ and $300 \mathrm{~V}$, respectively.

It is important to note that the operating criterion can be modified to suit different considerations, and is not limited only to the above mentioned.

From (22), (24) and (4), it can be noted that the grid-side power factor, the CUF and the operating currents are all only dependent on the operating speed and excitation voltage, when the grid voltage and system parameters are fixed. However, it is still very difficult to regulate these three factors at the same time under variable speed conditions, using real-time computed excitation voltage. This paper therefore proposed an approach, using the off-line method to pre-compute the optimum excitation voltages at different operating speeds. The obtained excitation voltages and corresponding speeds are stored in a two-dimensional (2-D) LUT. This is used to provide the optimum excitation winding reference voltage according to different operating rotor speeds in practice.

The off-line computation mainly consists of two parts: firstly, selecting the excitation voltages, satisfying all the requirements included in the criteria, for different speeds respectively; then, using the average filtering algorithm to obtain the final excitation voltages applied for different speeds.

The detailed determination process of the excitation voltage is described as follows:

i) Selecting the excitation voltages to generate power to the grid at near-unity power factor for different rotor speeds respectively.

The grid-side power factor can be calculated using (22), for different real and imaginary parts of the excitation winding phasor voltages, at any given rotor speed.

Fig. 9 shows the grid-side power factor variations with varying excitation voltages, when $s=-0.06$ and a $20 \mu \mathrm{F}$ compensation capacitor is connected with the power winding of the prototype generator in parallel. The blue shaded region in Fig. 9 shows the collection of the excitation voltages that satisfy near-unity power factor generation at this particular speed. This process is repeated to obtain the excitation voltages, satisfying the near-unity power factor generation, for different speeds.

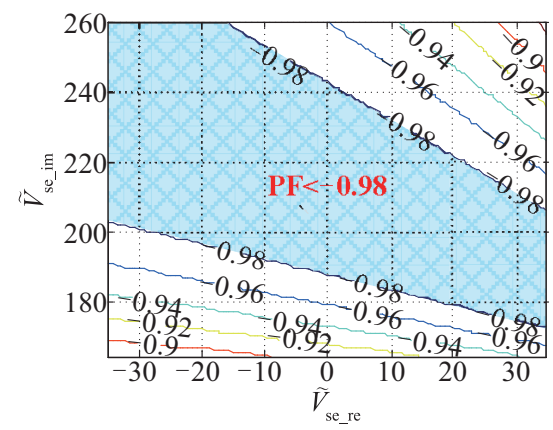

Fig. 9. The variations of the grid-side power factor $(\mathrm{PF})$ with respect to different excitation voltages for $s=-0.06, C_{\text {comp }}=20 \mu \mathrm{F}$.

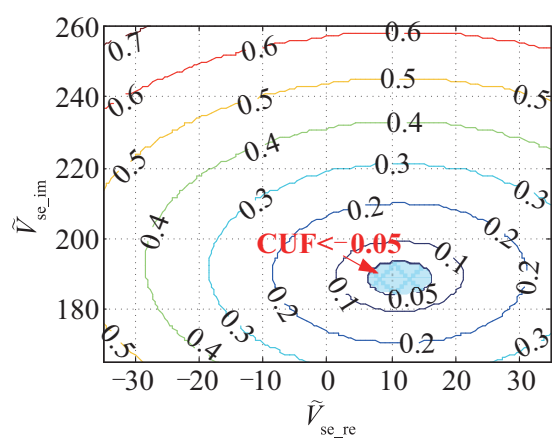

Fig. 10. The variations of the CUF with respect to different excitation voltages for $s=-0.06, C_{\text {comp }}=20 \mu \mathrm{F}$.

ii) Selecting the excitation voltages to operate the generator with CUF smaller than 0.05 for different rotor speeds respectively.

Similarly, the CUF can be calculated using (24), for different real and imaginary parts of the excitation winding phasor voltages at any given rotor speed.

Fig. 10 illustrates the variations of the CUF with varying excitation winding voltage for $s=-0.06$ and $C_{\text {comp }}=20 \mu \mathrm{F}$. The collection of the excitation voltages which allow the CUF smaller than 0.05 at this particular speed is marked by blue shaded region. This process is repeated to obtain the excitation voltages, satisfying the CUF requirement, for different speeds.

iii) Selecting the excitation voltages to operate the generator with its phase voltages and currents limited to specific values for different rotor speeds respectively.

For the phase voltages, due to this particular winding arrangement, the excitation voltage is not allowed to exceed the grid voltage when minimizing the unbalanced operation of the generator. The requirement associated with the phase voltage is therefore easily satisfied.

For the phase currents, both the power winding current and the excitation winding current can be calculated using (4), for different real and imaginary parts of the excitation winding phasor voltage at any given rotor speed. Figs. 11 and 12 illustrate the variations of the excitation winding current and the power winding current with varying excitation winding 


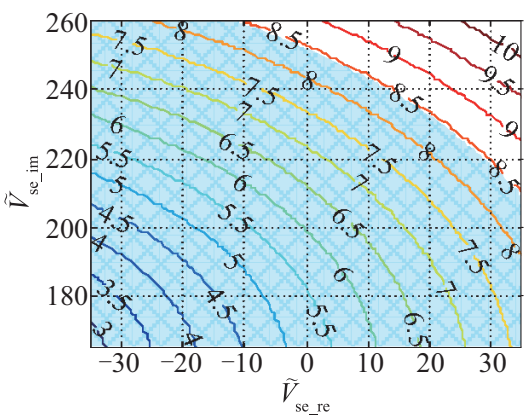

Fig. 11. The variations of the excitation winding current with respect to different excitation voltages for $s=-0.06, C_{\text {comp }}=20 \mu \mathrm{F}$.

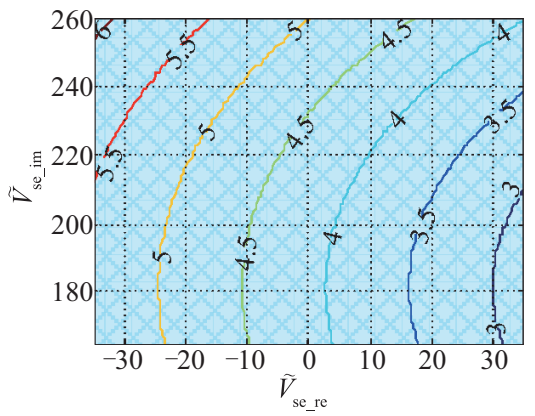

Fig. 12. The variations of the power winding current with respect to different excitation voltages for $s=-0.06, C_{\text {comp }}=20 \mu \mathrm{F}$.

voltage for slip $=-0.06$ and $C_{\text {comp }}=20 \mu \mathrm{F}$, respectively. The collection of the excitation voltages which makes the excitation winding current and power winding current smaller than 8.5 A are marked by blue shaded region, respectively in Figs. 11 and 12. As shown in Figs. 11 and 12, the power current is smaller than the excitation winding in general. This is because the power winding has a greater number of turns, thus needs less current. Likewise, this process is repeated to obtain the excitation voltages, satisfying the phase voltages and currents requirements, for different speeds.

iv) Selecting the collection of the excitation voltages which can operate the generator satisfying all the requirements included in the criteria for different rotor speeds respectively.

Once the excitation voltages, allowing the generator to satisfy each individual requirement included in the criteria, are selected respectively for a specific speed, the excitation voltages which allow the generator to satisfy all the requirements in the criteria can be readily obtained. Likewise, this process is repeated to obtain the excitation voltages, satisfying all requirements included in the criteria, for different speeds.

v) Obtaining the final excitation voltages for different rotor speeds.

Once the excitation voltages, allowing the generator to satisfy all the requirements in the criteria for a specific speed, are obtained, the final excitation voltage applied for this specific speed can be determined, using the average filtering

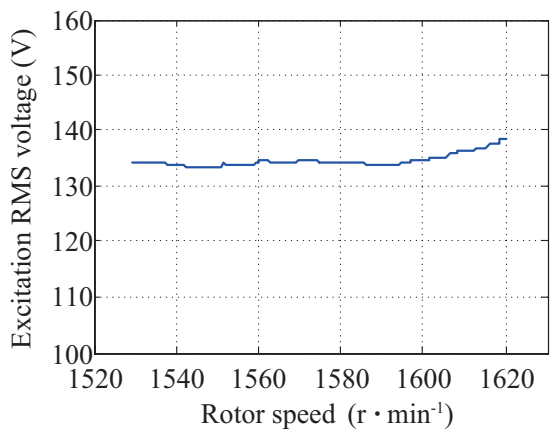

Fig. 13. The RMS values of the excitation voltages for different operating speeds.

algorithm, by:

$$
\begin{aligned}
& \widetilde{V}_{\text {se_re }}^{*}=\frac{\sum\left(\widetilde{V}_{\text {se1_re }}^{*}+\tilde{V}_{\text {se2_re }}^{*}+\cdots+\widetilde{V}_{\text {sen_re }}^{*}\right)}{n} \\
& \tilde{V}_{\text {se_im }}^{*}=\frac{\sum\left(\tilde{V}_{\text {sel_im }}^{*}+\tilde{V}_{\text {se2_im }}^{*}+\cdots+\widetilde{V}_{\text {sen_im }}^{*}\right)}{n}
\end{aligned}
$$

Where, $\tilde{V}_{\mathrm{se}}^{*}$ is the final excitation phasor voltage applied for this specific speed, $\tilde{V}_{\text {sel }}^{*}, \tilde{V}_{\mathrm{se} 2}^{*}, \ldots, \tilde{V}_{\mathrm{sen}}^{*}$ are the selected excitation phasor voltages which satisfy all the requirements included in the criteria, $n$ is the total number of these selected voltages. Likewise, this process is repeated to obtain the final excitation voltages applied for different speeds. The final excitation voltages are represented in the form of the phasor. For the practical use, these phasor values will be transformed into the RMS values of the excitation winding voltages and the phase difference between the excitation winding voltage and power winding voltage. These transformed values will be stored in the memory of the microprocessor as an LUT. Figs. 13 and 14 show the final RMS value of the excitation voltage and the phase difference for different operating speeds respectively. As shown in Figs. 13 and 14, the variations of the excitation RMS voltage and the phase difference with the rotor speed are smooth, thus ensuring the data continuity and smoothness across the operating rotor speed.

\section{Slip Estimation}

As mentioned above, the operating speed of the generator is required to determine which excitation voltage that will be applied from the LUT. Although the operating speed can be obtained directly by a speed sensor, it is undesirable because this causes degradation of reliability and adds extra cost. It is therefore quite necessary to propose a speed estimation method. For the grid-connected TSCAOI configured generator, its synchronous angular frequency is fixed with the grid angular frequency, to allow the speed estimation to be transformed into slip estimation. Thus, in this section, a slip estimation method, which is based on the fast time 


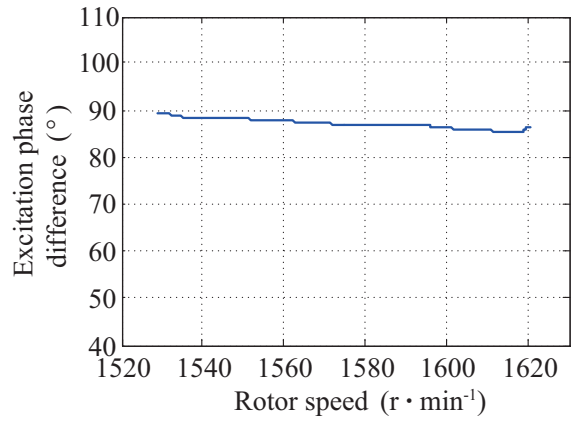

Fig. 14. The phase difference for different operating speeds.

domain symmetrical components decomposition algorithm, is presented, considering the cross coupling effects caused by the intrinsic asymmetry of the machine winding.

The space complex vector representation method, introduced in [41] for dynamic analysis of variable frequency ac drives, is used in this paper to simplify the derivations, and the machine variable represented in space complex vector can be given by:

$$
\vec{X}(t)=X_{\alpha}(t)+j X_{\beta}(t)
$$

Where $X$ can represent any variable of the stator and rotor circuits, $X_{\alpha}$ and $X_{\beta}$ are $\alpha$ and $\beta$ components of the variable $X$ in the stationary $\alpha \beta$ frame respectively and $j$ is the imaginary unity. The $X(t)$ can also be expressed by the summation of the positive and negative sequence components, as follow:

$$
\vec{X}(t)=X_{+}(t) e^{j\left(\omega_{s} t+\theta_{+}\right)}+X_{-}(t) e^{-j\left(\omega_{s} t+\theta_{-}\right)}
$$

In (28), subscript + and - represent positive and negative sequence components, $X_{+}(t)$ and $X_{-}(t)$, which are assumed to vary slowly with time, are the magnitudes of the positive and negative sequence components respectively, $\omega_{\mathrm{s}}$ is the synchronous angular frequency and $\theta_{+}$and $\theta_{-}$are the corresponding phase angles. (28) can be rewritten as below with $\gamma / \omega_{\mathrm{s}}$ delay.

$$
\vec{X}\left(t-\frac{\gamma}{\omega_{\mathrm{s}}}\right)=X_{+}\left(t-\frac{\gamma}{\omega_{\mathrm{s}}}\right) e^{j\left(\omega_{\mathrm{s}} t+\theta_{+}\right)-j \gamma} e^{-j \gamma}+X_{-}\left(t-\frac{\gamma}{\omega_{\mathrm{s}}}\right) e^{-j\left(\omega_{\mathrm{s}} t+\theta_{-}\right) j \gamma} e^{j \gamma}
$$

When the delay angle $\gamma$ is very small, above equation can be approximated as follow:

$$
\vec{X}\left(t-\frac{\gamma}{\omega_{\mathrm{s}}}\right)=X_{+}(t) e^{j\left(\omega_{\mathrm{s}} t+\theta_{+}\right)} e^{-j \gamma}+X_{-}(t) e^{-j\left(\omega_{\mathrm{s}} t+\theta_{-}\right) j \gamma} e^{j \gamma}
$$

Subtracting $\vec{X}(t) e^{j \gamma}$ from (30), equation below can be obtained.

$$
\vec{X}\left(t-\frac{\gamma}{\omega_{\mathrm{s}}}\right)-\vec{X}(t) e^{j \gamma}=-2 j \sin \gamma \cdot X_{+}(t) e^{j\left(\omega_{\mathrm{s}} t+\theta_{+}\right)}
$$

Thus

$$
X_{+}(t) e^{j\left(\omega_{\mathrm{s}} t+\theta_{+}\right)}=\frac{j}{2 \sin \gamma}\left[\vec{X}\left(t-\frac{\gamma}{\omega_{\mathrm{s}}}\right)-\vec{X}(t) e^{j \gamma}\right]
$$

(32) is the decomposition equation of the positive sequence component from the original signals. The positive sequence component can be described in terms of $\alpha$ and $\beta$ components as below by substituting (27) into (32).

$$
\begin{aligned}
X_{+}(t) e^{j\left(\omega_{\mathrm{s}} t+\theta_{+}\right)}= & \frac{1}{2 \sin \gamma}\left[X_{\beta}(t) \cos \gamma+X_{\alpha}(t) \sin \gamma-X_{\beta}\left(t-\frac{\gamma}{\omega_{\mathrm{s}}}\right)\right] \\
& +\frac{j}{2 \sin \gamma}\left[X_{\alpha}\left(t-\frac{\gamma}{\omega_{\mathrm{s}}}\right)-X_{\alpha}(t) \cos \gamma+X_{\beta}(t) \sin \gamma\right]
\end{aligned}
$$

The $\alpha$ and $\beta$ axis positive sequence components can be readily obtained by (33) as below:

$$
\begin{aligned}
& X_{\alpha+}(t)=\frac{1}{2} X_{\alpha}(t)-\frac{1}{2 \sin \gamma}\left[X_{\beta}\left(t-\frac{\gamma}{\omega_{\mathrm{s}}}\right)-X_{\beta}(t) \cos \gamma\right] \\
& X_{\beta+}(t)=\frac{1}{2} X_{\beta}(t)+\frac{1}{2 \sin \gamma}\left[X_{\alpha}\left(t-\frac{\gamma}{\omega_{\mathrm{s}}}\right)-X_{\alpha}(t) \cos \gamma\right]
\end{aligned}
$$

In the similar method, the negative sequence components in the $\alpha \beta$ frame can also be obtained as below:

$$
\begin{aligned}
& X_{\alpha-}(t)=\frac{1}{2} X_{\alpha}(t)+\frac{1}{2 \sin \gamma}\left[X_{\beta}\left(t-\frac{\gamma}{\omega_{\mathrm{s}}}\right)-X_{\beta}(t) \cos \gamma\right] \\
& X_{\beta-}(t)=\frac{1}{2} X_{\beta}(t)-\frac{1}{2 \sin \gamma}\left[X_{\alpha}\left(t-\frac{\gamma}{\omega_{\mathrm{s}}}\right)-X_{\alpha}(t) \cos \gamma\right]
\end{aligned}
$$

From (34) to (37), it is noted that the smaller the time delay $\gamma / \omega_{\mathrm{s}}$ is, the faster the response will be. However, the time delay $\gamma / \omega_{\mathrm{s}}$ cannot be too small as it will then be susceptible to the noise.

The block diagrams for decomposing the positive and negative sequence components from original signals are illustrated in Figs. 15 and 16, respectively.

The symmetrical components obtained from the above mentioned method can be employed to estimate the operating slip. The proposed slip estimation strategy is performed in the reference frame fixed to the decoupled positive sequence component of the stator flux linkage. This reference frame is rotating at frequency $\omega_{s^{+}}$, which denotes the positive synchronous frequency, and the estimation is based on the positive sequence components only. The positive sequence components based rotor circuit equations in the positive synchronously rotating frame can be directly derived from (1) in the stationary frame, due to the decoupled relationship between positive and negative sequence components in rotor circuits.

$$
\frac{\mathrm{d} \psi_{\mathrm{rd} d+}^{\prime+}}{\mathrm{d} t}+\frac{2}{3} R_{\mathrm{r}} i_{\mathrm{r} d+}^{\prime+}-\left(\omega_{\mathrm{s+}}-\omega_{\mathrm{r}}\right) \psi_{\mathrm{r} q+}^{\prime+}=0
$$




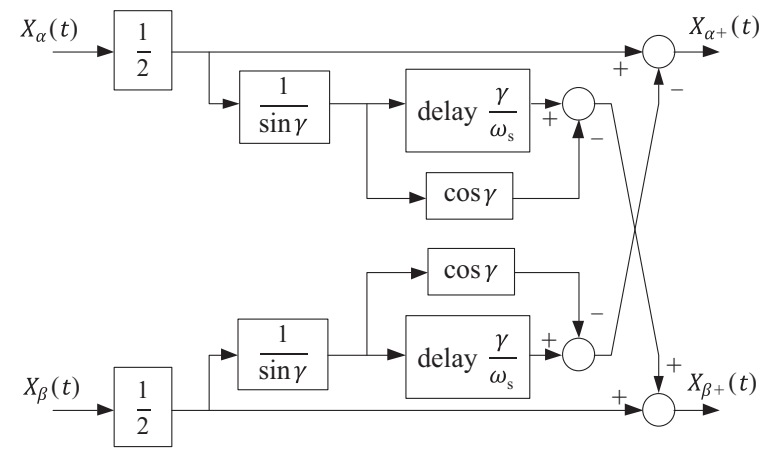

Fig. 15. The decomposition algorithm for positive sequence component.

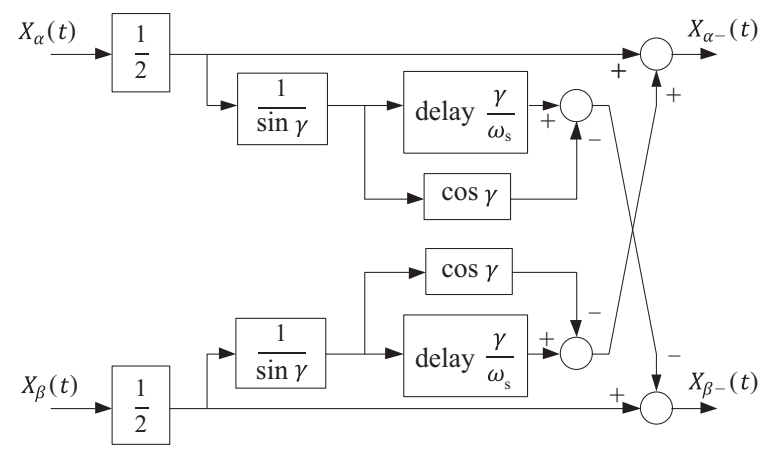

Fig. 16. The decomposition algorithm for negative sequence component.

$$
\frac{\mathrm{d} \psi_{\mathrm{r} q+}^{\prime+}}{\mathrm{d} t}+\frac{2}{3} R_{\mathrm{r}} i_{\mathrm{rq}+}^{\prime+}+\left(\omega_{\mathrm{s}+}-\omega_{\mathrm{r}}\right) \psi_{\mathrm{rq}+}^{\prime+}=0
$$

Where $\psi_{\mathrm{r}}^{\prime}$ and $i_{\mathrm{r}}^{\prime}$ represent the referred rotor flux linkage and rotor current respectively. The subscript + represents the positive sequence components and superscript + represents the components being evaluated in the positive synchronously rotating reference frame. The subscripts $d$ and $q$ are used to denote the direct and quadrature axis components in the reference frame respectively.

The positive sequence components of rotor currents in the positive synchronously rotating frame can also be written as

$$
\begin{aligned}
& i_{\mathrm{r} d+}^{\prime+}=\frac{1}{L_{\mathrm{r}}} \psi_{\mathrm{r} d+}^{\prime+}-\frac{L_{\mathrm{m}}}{L_{\mathrm{r}}} i_{\mathrm{s} d+}^{\prime+} \\
& i_{\mathrm{r} q+}^{\prime+}=\frac{1}{L_{\mathrm{r}}} \psi_{\mathrm{r} q+}^{\prime+}-\frac{L_{\mathrm{m}}}{L_{\mathrm{r}}} i_{\mathrm{s} q+}^{\prime+}
\end{aligned}
$$

Where $L_{\mathrm{r}}$ equals $\left(2 L_{\mathrm{ll}} / 3+L_{\mathrm{m}}\right)$. The rotor currents in (38) and (39) are inaccessible, they can be eliminated by substituting (40) and (41) into (38) and (39) respectively as

$$
\begin{aligned}
& \left(1+p T_{\mathrm{r}}\right) \psi_{\mathrm{rd}+}^{\prime+}-L_{\mathrm{m}} i_{\mathrm{sd} d}^{+}-T_{\mathrm{r}} \omega_{\mathrm{slip}} \psi_{\mathrm{rq}+}^{\prime+}=0 \\
& \left(1+p T_{\mathrm{r}}\right) \psi_{\mathrm{rq}+}^{\prime+}-L_{\mathrm{m}} i_{\mathrm{sq}+}^{+}+T_{\mathrm{r}} \omega_{\mathrm{slip}} \psi_{\mathrm{rd}+}^{\prime+}=0
\end{aligned}
$$

Where $p$ denotes $\mathrm{d} / \mathrm{d} t, \omega_{\text {slip }}$ denotes the slip angular velocity and $T_{\mathrm{r}}$ equals $L_{\mathrm{r}} /\left(2 R_{\mathrm{r}} / 3\right)$. In (42) and (43), $\psi_{\mathrm{r} d+}^{\prime+}$ and $\psi_{\mathrm{rq}+}^{\prime+}$ are to be eliminated and replaced by $\psi_{\mathrm{sd}+}^{+}$and $\psi_{\mathrm{s} q+}^{+}$. According to equivalent circuit model proposed in Section II, the $\psi_{\mathrm{s} d+}^{+}$and $\psi_{\mathrm{sq}+}^{+}$can be expressed as below. However, because of the intrinsic asymmetry of the stator circuit, $\psi_{\mathrm{sd}+}^{+}$and $\psi_{\mathrm{sq}+}^{+}$comprise terms resulting from the negative sequence components of stator currents.

$$
\begin{aligned}
& \psi_{\mathrm{sd}+}^{+}=\left(\frac{5}{6} L_{\mathrm{ls}}+L_{\mathrm{m}}\right) i_{\mathrm{sd}+}^{+}+\frac{1}{6} L_{\mathrm{ls}} i_{\mathrm{sd}-}^{+}+L_{\mathrm{m}} i_{\mathrm{rd}+}^{i^{+}} \\
& \psi_{\mathrm{s} q+}^{+}=\left(\frac{5}{6} L_{\mathrm{ls}}+L_{\mathrm{m}}\right) i_{\mathrm{sq}+}^{+}-\frac{1}{6} L_{\mathrm{ls}} i_{\mathrm{sd}-}^{+}+L_{\mathrm{m}} i_{\mathrm{rq}+}^{\prime+}
\end{aligned}
$$

The subscript - represents the negative sequence components, and the terms arising from the negative sequence components should be eliminated as only the positive sequence components of the stator currents has a direct concern in positive sequence components of rotor flux linkages production.

The positive sequence components of the rotor flux linkages can be expressed as below:

$$
\begin{aligned}
& \psi_{\mathrm{rd}+}^{\prime+}=\frac{L_{\mathrm{r}}}{L_{\mathrm{m}}} \psi_{\mathrm{s} d+\text { decoup }}^{+}+\left(L_{\mathrm{m}}-\frac{L_{\mathrm{r}} L_{\mathrm{s}}}{L_{\mathrm{m}}}\right) i_{\mathrm{sd} d+}^{+} \\
& \psi_{\mathrm{rq}+}^{\prime+}=\frac{L_{\mathrm{r}}}{L_{\mathrm{m}}} \psi_{\mathrm{s} q, \text { decoup }}^{+}+\left(L_{\mathrm{m}}-\frac{L_{\mathrm{r}} L_{\mathrm{s}}}{L_{\mathrm{m}}}\right) i_{\mathrm{sq}+}^{+}
\end{aligned}
$$

Where $L_{\mathrm{s}}$ equals $\left(5 L_{\mathrm{ls}} / 6+L_{\mathrm{m}}\right), \psi_{\mathrm{s} d+\text {,decoup }}^{+}$and $\psi_{\mathrm{s} q+\text {,decoup }}^{+}$, which are the decoupled terms, can be written as below:

$$
\begin{aligned}
& \psi_{\mathrm{s} d, \text { decoup }}^{+}=\left(\frac{5}{6} L_{\mathrm{ls}}+L_{\mathrm{m}}\right) i_{\mathrm{sd}+}^{+}+L_{\mathrm{m}} i_{\mathrm{rd}+}^{i^{+}} \\
& \psi_{\mathrm{sq}+\text { decoup }}^{+}=\left(\frac{5}{6} L_{\mathrm{ls}}+L_{\mathrm{m}}\right) i_{\mathrm{s} q+}^{+}+L_{\mathrm{m}} i_{\mathrm{r} q+}^{++}
\end{aligned}
$$

Substituting (46) and (47) into (43) obtains

$$
\left(1+p T_{\mathrm{r}}\right) \psi_{\mathrm{s} q, \text { decoup }}^{+}=\left(1+\sigma p T_{\mathrm{r}}\right) L_{\mathrm{s}} i_{\mathrm{sq}+}^{+}-T_{\mathrm{r}} \omega_{\text {slip }}\left(\psi_{\mathrm{sd} d, \text { decoup }}^{+}-\sigma L_{\mathrm{s}} i_{\mathrm{sdd}}^{+}\right)
$$

where $\sigma=1-L_{\mathrm{m}}^{2} / L_{\mathrm{s}} L_{\mathrm{r}}$. With direct axis of the reference frame being fixed to the decoupled positive sequence component of the stator flux linkage, $\psi_{\text {sd } t \text {,decoup }}^{+}=0$ and $\omega_{\text {slip }}$ can be therefore written as:

$$
\omega_{\text {slip }}=\frac{\left(1+\sigma p T_{\mathrm{r}}\right) L_{\mathrm{s}} i_{\mathrm{s} q+}^{+}}{T_{\mathrm{r}}\left(\psi_{\mathrm{s} d+\text {,decoup }}^{+}-\sigma L_{\mathrm{s}} i_{\mathrm{s} d+}^{+}\right)}
$$

Fig. 17 shows the block diagram of the proposed slip estimation scheme, and the stator flux estimation can be easily realized by

$$
\begin{gathered}
\psi_{\mathrm{se}}=\int\left(v_{\mathrm{se}}-R_{\mathrm{s}} i_{\mathrm{se}}\right) \mathrm{d} t \\
\psi_{\mathrm{so}}^{\prime}=\int\left(v_{\mathrm{so}}^{\prime}-\frac{2}{3} R_{\mathrm{s}} i_{\mathrm{so}}^{\prime}\right) \mathrm{d} t
\end{gathered}
$$




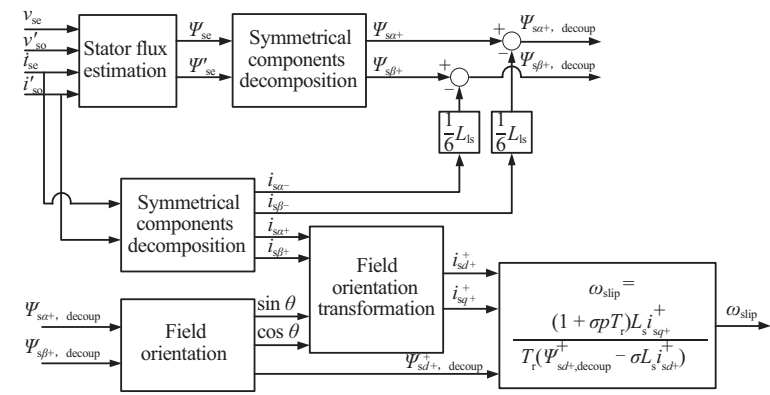

Fig. 17. Block diagram of the proposed slip estimation scheme.

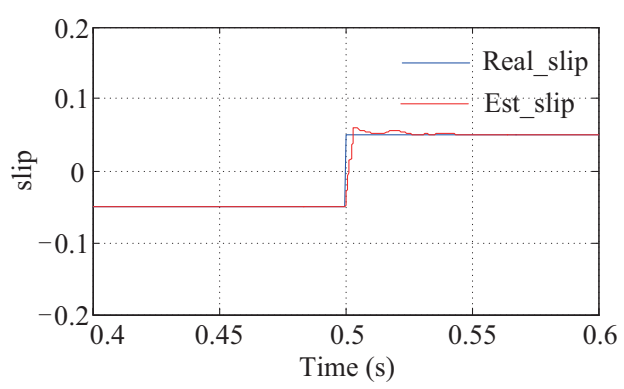

(a)

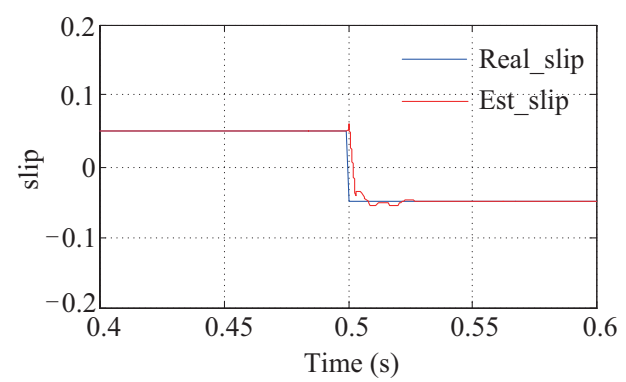

(b)

Fig. 18. Step response of the slip estimation.

Fig. 18 shows the simulated step response of the proposed slip estimation scheme. The estimated and real slip are in good accordance. Furthermore, the proposed slip estimation scheme shows a very good performance in settling and rising time.

\section{TSCAOI Configured Single-Phase Grid-ConNeCted INDUCTION GENERATOR}

The block diagram of the TSCAOI configured singlephase grid-connected induction generator is illustrated in Fig.19. As shown in Fig. 19, the excitation winding of the TSCAOI configured generator is fed by the single-phase bidirectional converter and the power winding, constructed by the two series-connected windings, is connected with the single-phase AC grid. The measured winding currents and voltages are provided to the slip estimator to estimate the slip angular frequency. The estimated slip angular frequency or its equivalent rotor speed is fed into the pre-defined LUT to select the reference voltage of the excitation winding. In order to generate the actual excitation voltage, besides the reference

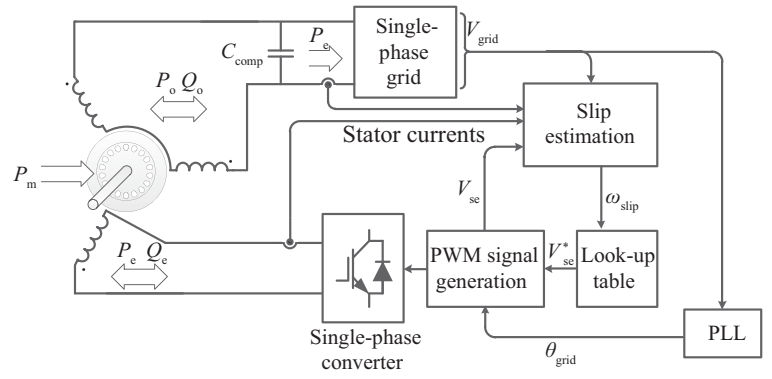

Fig. 19. Block diagram of the proposed control scheme for grid connected TSCAOI generator.

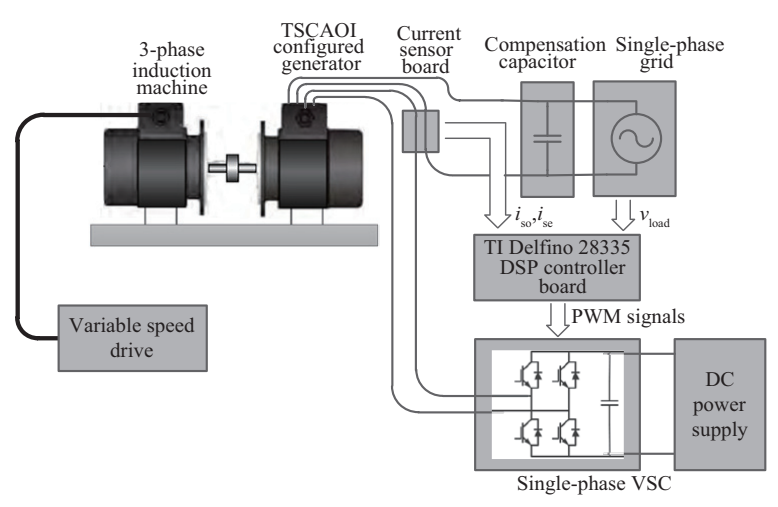

Fig. 20. Experimental setup.

voltage, the grid phase angle $\theta_{\text {grid }}$ is also required, and it is obtained from the phase-locked loop (PLL).

\section{RESULTS AND DisCUSSION}

In order to demonstrate the viability of the proposed control strategy and investigate both the behaviour and limitations of the grid-connected TSCAOI generator, simulations and experimental tests have been performed under various steadystate and transient conditions.

A four-pole $3 \mathrm{~kW}, 400 \mathrm{~V}$ cage induction machine was configured in the TSCAOI winding arrangement for both simulations and experiments. The parameters of this cage induction machine are given in the Appendix. Based on this prototype generator, a small-scale generation system was implemented on the experimental platform shown in Fig. 20.

In the experiment, the prototype generator was mechanically coupled with another induction machine controlled by a variable-speed drive (VSD) to emulate the variable-speed prime mover. The $230 \mathrm{~V} / 50 \mathrm{~Hz}$ single-phase grid was connected with the power winding, and a single-phase voltage source converter (VSC) was connected with the excitation winding. The control software of the single-phase VSC was developed on a TI Delfino 28335 controller board. Voltage and current sensors were used to measure the grid voltage and the winding currents of the generator, respectively. The feedback signals of the gird voltage and the winding currents were read by the controller board through $\mathrm{A} / \mathrm{D}$ (analog to digital) 


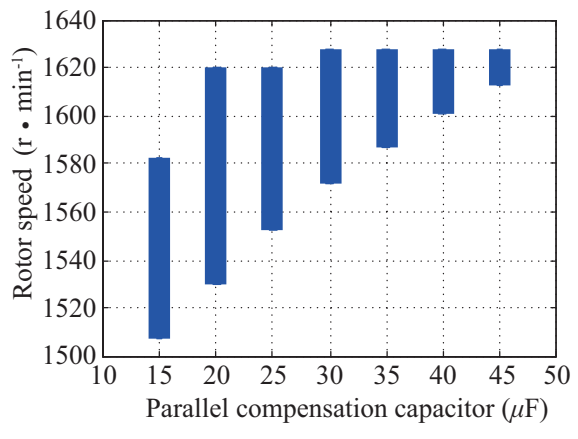

Fig. 21. The operating speed range for different parallel compensation capacitors.

converter. The LUT presented in Fig. 20 was stored in the controller board to select the proper excitation winding voltage. Based on the selected excitation winding reference voltage and grid phase angle, the PWM signals for the switches in the single-phase VSC were generated by the controller board, accordingly.

Before the detailed simulated and experimental investigation, the value of the compensation capacitor must be first determined. The compensation capacitor, connected with the single-phase grid in parallel, is used to reduce the reactive power requirement of the grid. Thus, it plays a vital role in correcting the grid-side power factor, and then has a significant impact on the system operating range.

Unlike the standalone TSCAOI configured generator, the operating range of the gird-connected TSCAOI configured generator is only determined by its speed range. The speed range can be indirectly obtained, using the determination method proposed for the excitation winding voltage in Section iii. For a given rotor speed, the determination method can find whether there exists an excitation voltage, allowing this prototype generator to satisfy the criteria described above, with a specific compensation capacitor. If there exists such an excitation voltage, this particular rotor speed is applicable for the generator; otherwise, this particular rotor speed is not applicable.

Fig. 21 illustrates the simulated operating speed range of the prototype generator with different compensation capacitors using the proposed criteria. According to Fig. 21, the $20 \mu \mathrm{F}$ capacitor providing the maximum operating range, was therefore selected.

Fig. 22(a) and (b) shows the variations in the steadystate currents of the excitation winding and power winding respectively with varying rotor speeds. As shown in Fig. 22, experimental and simulated results are in good agreement, and both excitation winding and power winding currents increase linearly with increasing rotor speeds. It is important to note that, the excitation winding current is proportional to the power winding current by a factor approximately equalling to $\sqrt{3}$, which is the turns ratio between the power winding and excitation winding, thus indicating the generator is operated

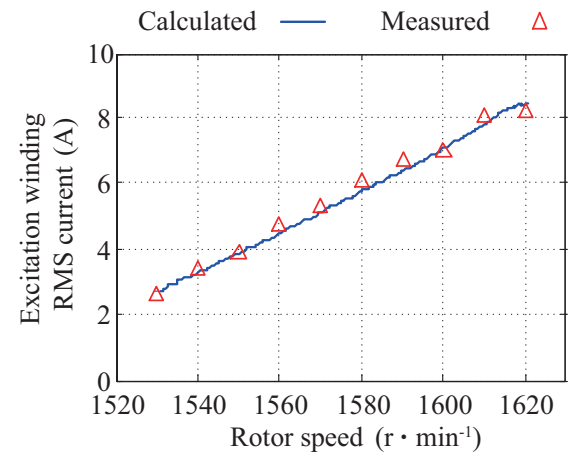

(a)

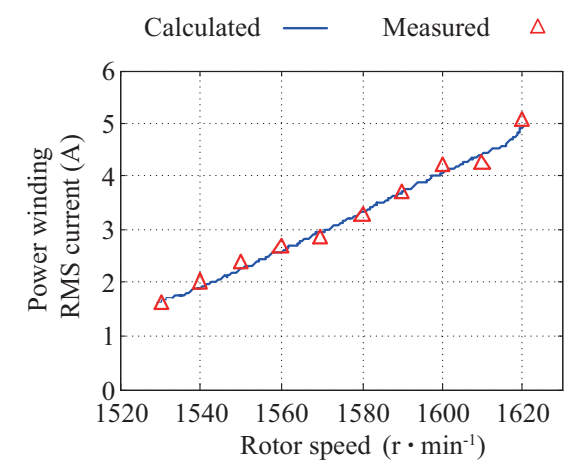

(b)

Fig. 22. (a) Excitation winding current and (b) power winding current vs. rotor speeds.

with minimum unbalance.

The variations in the active power provided by the excitation winding and power winding versus the rotor speeds are shown in Fig. 23(a) and (b), respectively. The negative power indicates that the active power is supplied by both power winding and excitation winding. Unlike the standalone TSCAOI configured generator, which can be operated both at sub- and super-synchronous rotor speeds, the grid-connected generator is limited to be operated at only super-synchronous speeds by the given operating criteria. Thus, the excitation winding keeps generating active power, and the generated power is fed back through the bi-directional converter to the ESS under all operating conditions. However, if the operating criterion is changed, the grid-connected generator is also able to operate at both sub- and super-synchronous rotor speeds and active power can also be provided from the converter side. The similar variations of the generated active power versus rotor speeds can be observed in Fig. 23(a) and (b), further indicating that the generator is operated with minimum unbalance. In addition, it is noticeable that the maximum generated active power is about $2 \mathrm{~kW}$, when the generator is operated at highest speeds.

Fig. 24(a) and (b), respectively, demonstrates the variations of the reactive power supplied by the power winding and excitation winding with different rotor speeds. As illustrated in Fig. 24, the reactive power requirements increase with the increasing rotor speeds. Furthermore, as expected, the presence of the compensation capacitor significantly reduces the 


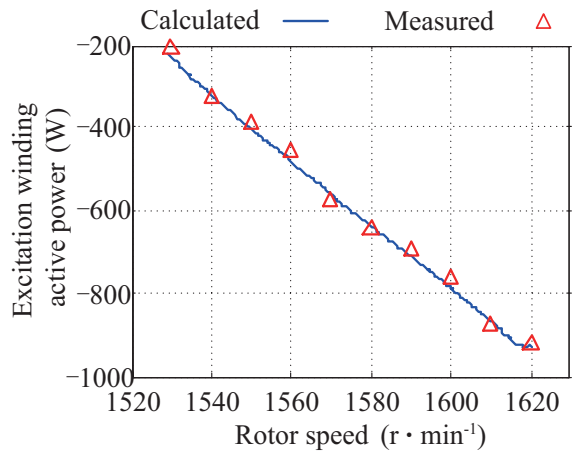

(a)

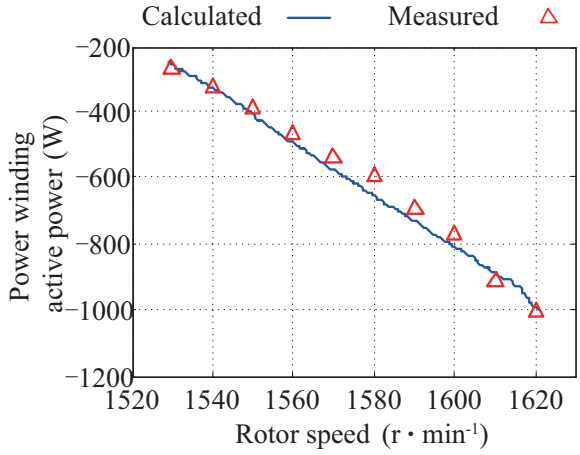

(b)

Fig. 23. Active power generation of the (a) excitation winding and (b) power winding vs. rotor speeds.

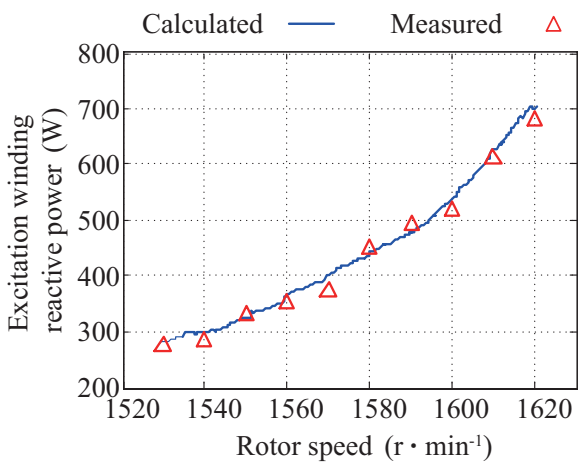

(a)

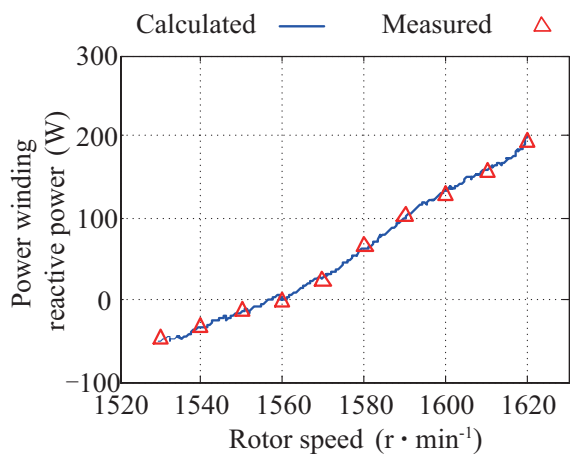

(b)

Fig. 24. Reactive power generation of the (a) excitation winding and (b) power winding vs. rotor speeds.

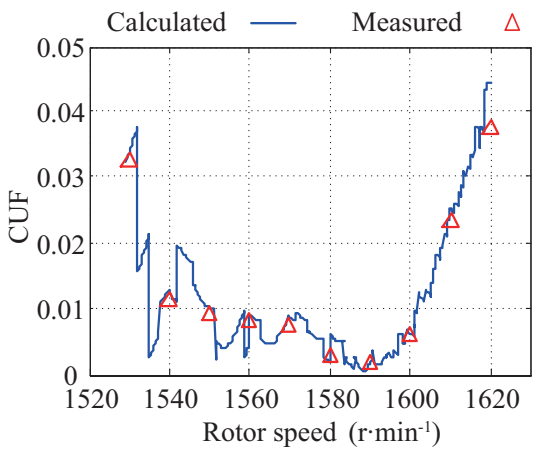

(a)

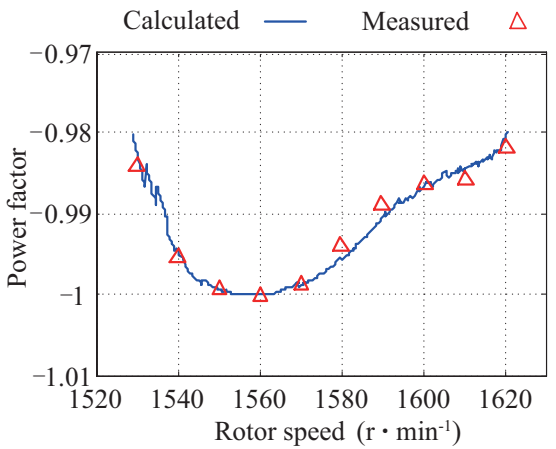

(b)

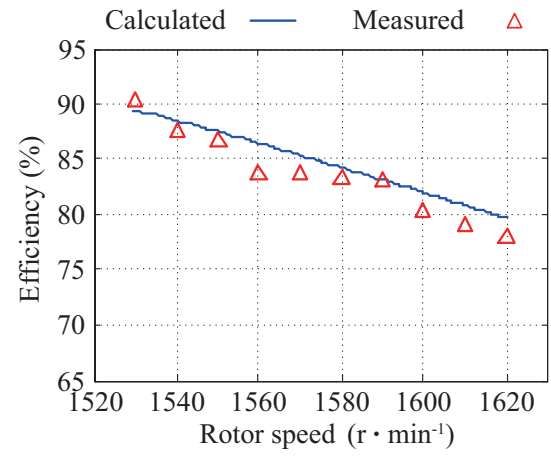

(c)

Fig. 25. (a) CUF, (b) power factor and (c) efficiency vs. rotor speeds.

reactive power requirement of the grid side. Meanwhile, as the generator is required to be operated with minimum unbalance, the reactive power consumed by the compensation capacitor, which is $332.2 \mathrm{VA}$ in this case, is approximately equal to the difference between the reactive power provided by the gridside and converter-side.

Fig. 25(a) shows the variation of CUF with different rotor speeds. As shown in Fig. 25(a), the variation of CUF is strictly limited within the given range, which is 0 to 0.05 in this case. The small variations of CUF further indicate the generator is operated with minimum unbalance. It is interesting to note that the magnitude of unbalance is intensified when the operating speed approaches to the lowest and highest speed limitations. The variations of the power factor versus the rotor speeds are shown in Fig. 25(b). As shown in Fig. 25(b), the experimental and simulated results are also in good agreement and the power 


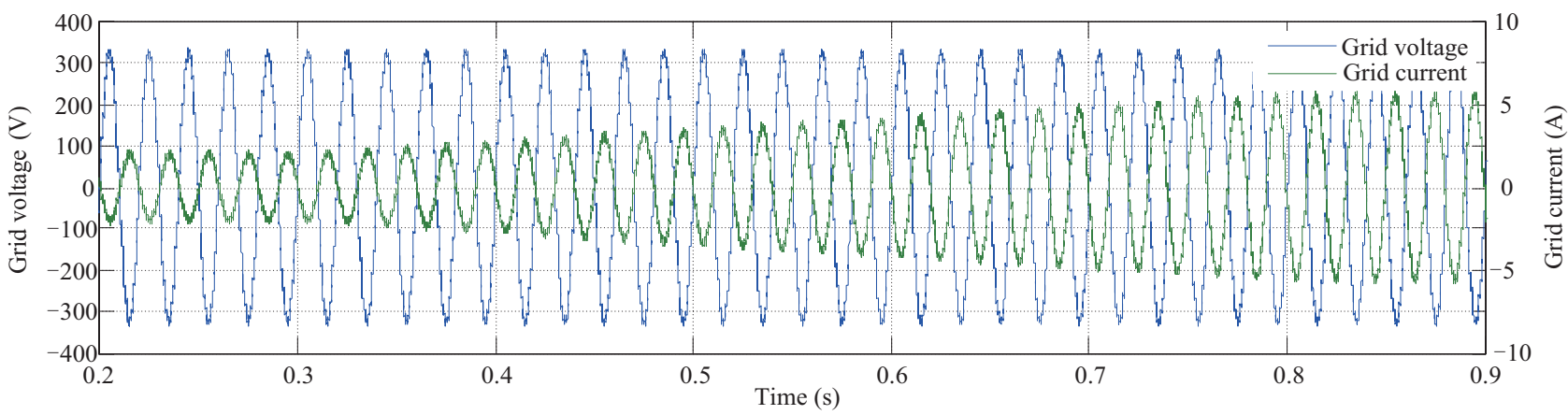

Fig. 26. Experimental transient waveforms of grid voltage and current at acceleration.

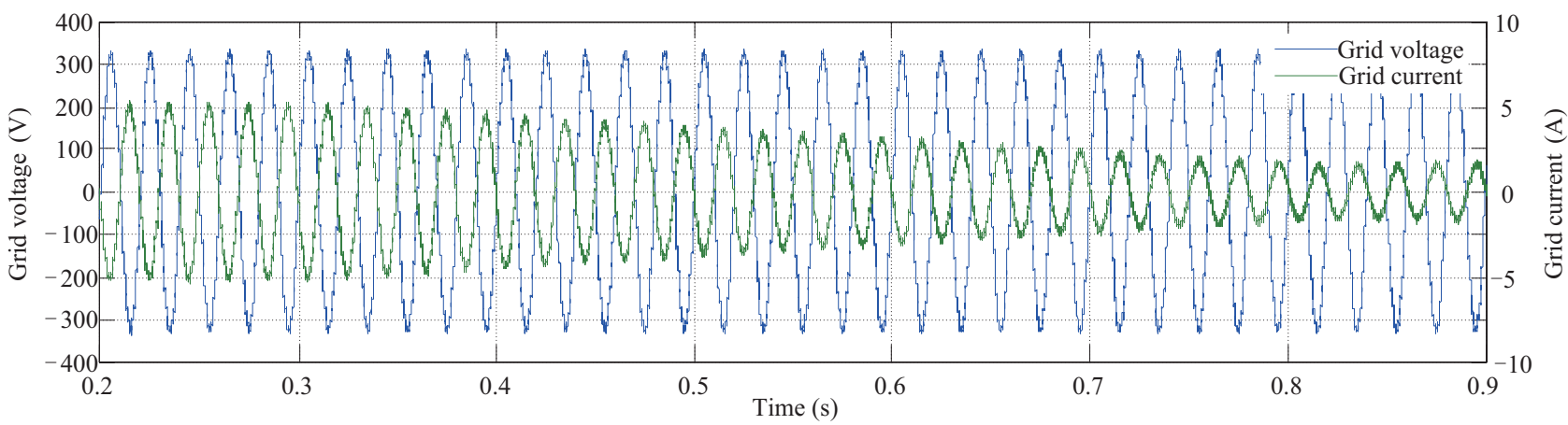

Fig. 27. Experimental transient waveforms of grid voltage and current at deceleration.

factor is well regulated below -0.98 , ensuring that generated power is delivered to the grid with near unity power factor. However, the power factor becomes poor at the lowest and highest speeds. The performance of the proposed generator was also evaluated using the efficiency, as shown in Fig. 25(c). The small difference between the experimental and simulated results can be attributed to losses that were not included in the mathematical model. A maximum efficiency of approximately $90 \%$ was achieved when the generator was operated at the lowest rotor speeds with minimum load. However, as speed and load increase, the efficiency begins to decrease linearly to an approximately $80 \%$.

Figs. 26 and 27 show the transient experimental waveforms of the grid voltage and current of the proposed single-phase grid-connected TSCAOI generator during the change of speed. The acceleration test results, which are shown in Fig. 26, were obtained by linearly increasing the rotor speed from 1540 $\mathrm{rpm}$ at $0.3 \mathrm{~s}$ to $1600 \mathrm{rpm}$ within $0.5 \mathrm{~s}$ and the deceleration test results, shown in Fig. 27, were obtained by linearly decreasing the rotor speed from $1600 \mathrm{rpm}$ at $0.3 \mathrm{~s}$ to $1540 \mathrm{rpm}$ within $0.5 \mathrm{~s}$. As can be seen, the system behaves as expected. Under the proposed control scheme, the grid current varies smoothly with the varying speeds and the power is still delivered to the grid at near unity power factor when the speed was changed.

\section{CONCLUSION}

A variable-speed grid-connected TSCAOI configured SCIG for single-phase electricity generation has been described in this paper. A mathematical model has been proposed to investigate the behaviour and limitations of this grid-connected generator. Based on the mathematical model, a control scheme has been proposed for the grid-connected TSCAOI configured generator. The control scheme incorporates an LUT, enabling the electricity generation at near-unity power factor and limiting the unbalanced operation of the generator. In addition, a slip estimation method, which enables speedsensorless control of the generator, has also been proposed for simplifying the system. The validity of the proposed generator concept has been verified by using both simulations and experimental evidence of a prototype generator. Both analytical and measured results indicate the proposed technique is viable and allows for variable-speed electricity generation at near unity power factor. The proposed generator, which is easy to be implemented and low in cost, is an ideal candidate for smallscale renewable energy distributed generation.

\section{APPENDIX}

Prototype: A squirrel cage $3 \mathrm{~kW}$ TECO four-pole $400 \mathrm{~V} / 50$ $\mathrm{Hz}$ induction machine, which has the following parameters:

$$
\begin{gathered}
R_{\mathrm{s}}=1.5 \Omega \\
R_{\mathrm{r}}=2 \Omega \\
L_{\mathrm{ls}}=0.011 \mathrm{H} \\
L_{\mathrm{lr}}=0.011 \mathrm{H} \\
L_{\mathrm{M}}=0.214 \mathrm{H} \\
J=0.01 \mathrm{~kg} \cdot \mathrm{m}^{2}
\end{gathered}
$$




\section{REFERENCES}

[1] H. Boogaard, K. Walker, and A. J. Cohen, "Air pollution: the emergence of a major global health risk factor,"in International Health, vol. 11, pp. 417-421, 2019.

[2] J. Lelieveld, K. Klingmüller, A. Pozzer, R. Burnett, A. Haines, and V. Ramanathan, "Effects of fossil fuel and total anthropogenic emission removal on public health and climate," in Proceedings of the National Academy of Sciences, vol. 116, pp. 7192-7197, 2019.

[3] T. Adefarati and R. C. Bansal, "Integration of renewable distributed generators into the distribution system: a review," in IET Renewable Power Generation, vol. 10, no. 7, pp. 873-884, 2016.

[4] A. M. Bouzid, J. M. Guerrero, A. Cheriti, M. Bouhamida, P. Sicard, and M. Benghanem, "A survey on control of electric power distributed generation systems for microgrid applications," in Renewable and Sustainable Energy Reviews, vol. 44, pp. 751-766, 2015.

[5] REN21, "Renewables 2019: Global status report," REN21 Secretariat, 2019.

[6] M. O. Durham and R. Ramakumar, "Power system balancers for an induction generator," in IEEE Transactions on Industry Applications, vol. IA-23, no. 6, pp. 1067-1072, Nov. 1987.

[7] O. J. Smith, "Three-phase induction generator for single-phase line," in IEEE Transactions on Energy Conversion, vol. EC-2, no. 3, pp. 382-387, Sep. 1987.

[8] T. F. Chan and L. L. Lai, "Single-phase operation of a three-phase induction generator with the Smith connection," in IEEE Power Engineering Review, vol. 22, pp. 58-58, Apr. 2002.

[9] T. F. Chan and L. L. Lai, "A novel excitation scheme for a stand-alone three-phase induction generatorsupplying single-phase loads," in IEEE Transactions on Energy Conversion, vol. 19, no. 1, pp. 136-143, Mar. 2004.

[10] T. F. Chan, L. L. Lai, and L. T. Yan, "A coupled circuit and field analysis of a three-phase induction motor with the Smith connection," in IEEE Transactions on Magnetics, vol. 42, no. 4, pp. 1315-1318, Apr. 2006.

[11] T. F. Chan, "Performance analysis of a three-phase induction generator self-excited with a single capacitance," in IEEE Transactions on Energy Conversion, vol. 14, no. 4, pp. 894-900, Dec. 1999.

[12] T. F. Chan and L. L. Lai, "A novel single-phase self-regulated self-excited induction generator using a three-phase machine," in IEEE Transactions on Energy Conversion, vol. 16, pp. 204-208, Jun. 2001.

[13] L. Wang and R. Y. Deng, "A novel analysis of an autonomous three-phase delta-connected induction generator with one capacitor," in Proceedings of 2006 IEEE Power Engineering Society General Meeting, Montreal, Que., 2006, pp. 6.

[14] T. Fukami, Y. Kaburaki, S. Kawahara, and T. Miyamoto, "Performance analysis of a self-regulated self-excited single-phase induction generator using a three-phase machine," in IEEE Transactions on Energy Conversion, vol. 14, no. 3, pp. 622-627, Sep. 1999.

[15] S. N. Mahato, S. P. Singh, and M. P. Sharma, "Capacitors required for maximum power of a self-excited single-phase induction generator using a three-phase machine," in IEEE Transactions on Energy Conversion, vol. 23, no. 2, pp. 372-381, Jun. 2008.

[16] S. N. Mahato, S. P. Singh, and M. P. Sharma, "Dynamic behavior of a single-phase self-excited induction generator using a three-phase machine feeding single-phase dynamic load," in International Journal of Electrical Power \& Energy Systems, vol. 47, pp. 1-12, May 2013.

[17] T. F. Chan and L. L. Lai, "Single-phase operation of a three-phase induction generator using a novel line current injection method," in IEEE Transactions on Energy Conversion, vol. 20, no. 2, pp. 308-315, Jun. 2005.

[18] S. S. Murthy, B. Singh, S. Gupta, and B. M. Gulati, "General steady-state analysis of three-phase self-excited induction generator feeding threephase unbalanced load/single-phase load for stand-alone applications," in IEE Proceedings-Generation, Transmission and Distribution, vol. 150, no. 1, pp. 49-55, Jan. 2003.

[19] T. F. Chan and L. L. Lai, "Capacitance requirements of a three-phase induction generator self-excited with a single capacitance and supplying a single-phase load," in IEEE Transactions on Energy Conversion, vol. 17, no. 1, pp. 90-94, Mar. 2002.

[20] O. Ojo, "Performance of self-excited single-phase induction generators with shunt, short-shunt and long-shunt excitation connections," in IEEE Transactions on Energy Conversion, vol. 11, no. 3, pp. 477-482, Sep. 1996

[21] S. S. Murthy, "A novel self-induced self-regulated single phase induction generator. I. Basic system and theory," in IEEE Transactions on Energy Conversion, vol. 8, no. 3, pp. 377-382, Sep. 1993.

[22] E. Muljadi and T. A. Lipo, "Series compensated PWM inverter with battery supply applied to an isolated induction generator," in IEEE Transactions on Industry Applications, vol. 30, no. 4, pp. 1073-1082, Jul.-Aug. 1994.

[23] I. Boldea and S. A. Nasar, The Induction Machine Handbook. Boca Raton, FL: CRC Press, 2002.

[24] S. P. Singh, B. Singh, and M. P. Jain, "Performance characteristics and optimum utilization of a cage machine as capacitance excited induction generator," in IEEE Transactions on Energy Conversion, vol. 5, no. 4, pp. 679-685, Dec. 1990.

[25] L. L. Lai and T. F. Chan, Distributed generation: Induction and Permanent Magnet Generator. New Jersey, USA: John Wiley \& Sons, 2008.

[26] T. F. Chan and L. L. Lai, "Phase balancing for a self-excited induction generator," in Proceedings of DRPT2000. International Conference on Electric Utility Deregulation and Restructuring and Power Technologies. Proceedings (Cat. No.00EX382), London, UK, 2000, pp. 602-607.

[27] T. F. Chan and L. L. Lai, "Steady-state analysis and performance of a stand-alone three-phase induction generator with asymmetrically connected load impedances and excitation capacitances," in IEEE Transactions on Energy Conversion, vol. 16, no. 4, pp. 327-333, Dec. 2001

[28] M. G. Simoes, B. K. Bose, and R. J. Spiegel, "Design and performance evaluation of a fuzzy-logic-based variable-speed wind generation system," in IEEE Transactions on Industry Applications, vol. 33, no. 4, pp. 956-965, Jul.-Aug. 1997.

[29] B. K. Bose, "Energy, environment, and advances in power electronics," in Proceedings of the 2000 IEEE International Symposium on Industrial Electronics (Cat. No.00TH8543), Cholula, Puebla, Mexico, 2000, pp. TU1-T14, vol.1.

[30] R. Bojoi, D. Roiu, G. Griva, and A. Tenconi, "Single-phase gridconnected distributed generation system with maximum power tracking," in Proceedings of 2010 12th International Conference on Optimization of Electrical and Electronic Equipment, Basov, 2010, pp. 1131-1137.

[31] C. P. Ion and C. Marinescu, "Stand-alone micro-hydro power plant with induction generator supplying single phase loads," in Journal of Renewable and Sustainable Energy, vol. 5, 2013.

[32] C. P. Ion, I. Serban, and C. Marinescu, "Single-phase operation of an autonomous three-phase induction generator using a VSI-DL control system," in Proceedings of 2008 11th International Conference on Optimization of Electrical and Electronic Equipment, Brasov, 2008, pp. 333-338.

[33] S. S. Murthy, Ramrathnam, M. S. L. Gayathri, K. Naidu, and U. Siva, "A novel digital control technique of electronic load controller for SEIG based micro hydel power generation," in Proceedings of 2006 International Conference on Power Electronic, Drives and Energy Systems, New Delhi, 2006, pp. 1-5.

[34] B. Singh, S. S. Murthy, and S. Gupta, "Analysis and design of electronic load controller for self-excited induction generators," in IEEE Transactions on Energy Conversion, vol. 21, no. 1, pp. 285-293, Mar. 2006

[35] S. Gao, G. Bhuvaneswari, S. S. Murthy, and U. Kalla, "Efficient voltage regulation scheme for three-phase self-excited induction generator feeding single-phase load in remote locations," in IET Renewable Power Generation, vol. 8, pp. 100-108, Mar. 2014

[36] A. Chatterjee and D. Chatterjee, "An improved excitation control technique of three-phase induction machine operating as dual winding generator for micro-wind domestic application," in Energy Conversation \& Management, vol. 98, pp. 98-106, 2015.

[37] A. Chatterjee and D. Chatterjee, "Analysis and control of photovoltaicassisted three-phase induction machine operating as single-phase microwind generator," in IET Generation, Transmission \& Distribution, vol. 
10, pp. 2165-2176, Jun. 2016.

[38] U. K. Madawala, T. Geyer, J. B. Bradshaw, and D. M. Vilathgamuwa, "Modeling and analysis of a novel variable-speed cage induction generator," in IEEE Transactions on Industrial Electronics, vol. 59, no. 2, pp. 1020-1028, Feb. 2012.

[39] J. Soltani and N. R. Abjadi, "A novel stand-alone single-phase induction generator using a three-phase machine and a single-phase PWM inverter," in International Journal of Engineering Transaction, vol. A, pp. 259-268, 2003.

[40] Z. Wang, U. K. Madawala, T. H. Liu, and D. J. Thrimawithana, "Steadystate characteristis of 3-phase cage induction generators in TSCAOI configuration," in Proceedings of 2015 IEEE 2nd International Future Energy Electronics Conference (IFEEC), Taipei, 2015, pp. 1-6.

[41] D. W. Novotny and T. A. Lipo, Vector Control and Dynamics of $A C$ Drives. Oxford, U K: Clarendon,1996.

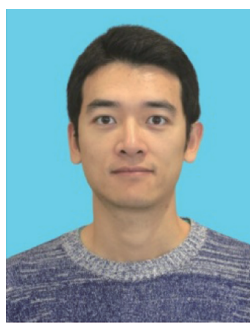

Zhijia Wang received the B.E. degree in electrical engineering and automation from the Harbin Institute of Technology, Harbin, China, in 2010, and the M.Sc. degree in automotive engineering from Bath University, Bath, U.K., in 2012. He is currently pursuing the Ph.D. degree with the Department of Electrical and Computer Engineering, the University of Auckland, Auckland, New Zealand. His current research interests include power electronics, electric machine drive and design, and electric vehicles.

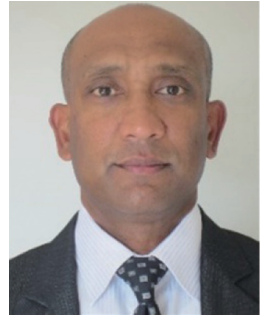

Udaya Kumara Madawala graduated with B.Sc. (electrical engineering) (Hons) from the University of Moratuwa, SriLanka in 1986 and received his $\mathrm{PhD}$ (Power electronics) from the University of Auckland, New Zealand in 1993 as a commonwealth Doctoral Scholar. At the completion of his Ph.D., he was employed by Fisher \& Paykel Ltd., New Zealand, as a Research and Development Engineer to develop new technologies for motor drives. In 1997 he joined the Department of Electrical and Computer Engineering at the University of Auckland where he is a Full Professor at present. His research interests are in the filds of wireless power transfer (WPT), power electronics, V2G applications and renewable energy. Udaya is a Fellow of the IEEE and a Distinguished Lecturer of the IEEE Power Electronic Society (PELS), and has over 30 years of both industry and research experience in the filds of power electronics and energy. He has served both the IEEE Power Electronics and Industrial Electronics Societies in numerous roles, relating to editorial, advisory, conference, technical committee and chapter activities. 